\title{
Pre-industrial to end 21st century projections of tropospheric ozone from the Atmospheric Chemistry and Climate Model Intercomparison Project (ACCMIP)
}

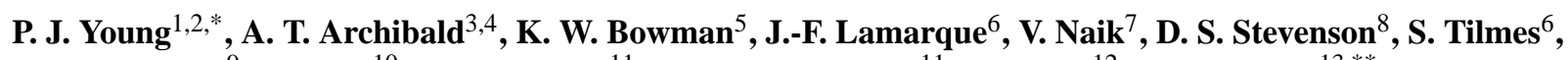
A. Voulgarakis ${ }^{9}$, O. Wild ${ }^{10}$, D. Bergmann ${ }^{11}$, P. Cameron-Smith ${ }^{11}$, I. Cionni ${ }^{12}$, W. J. Collins ${ }^{13}{ }^{* *}$, S. B. Dalsøren ${ }^{14}$,

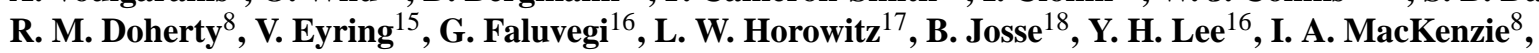
T. Nagashima ${ }^{19}$, D. A. Plummer ${ }^{20}$, M. Righi ${ }^{15}$, S. T. Rumbold ${ }^{13}$, R. B. Skeie ${ }^{14}$, D. T. Shindell ${ }^{16}$, S. A. Strode ${ }^{21,22}$, K. Sudo ${ }^{23}$, S. Szopa ${ }^{24}$, and G. Zeng ${ }^{25}$

${ }^{1}$ Cooperative Institute for Research in the Environmental Sciences, University of Colorado-Boulder, Boulder, Colorado, USA

${ }^{2}$ Chemical Sciences Division, NOAA Earth System Research Laboratory, Boulder, Colorado, USA

${ }^{3}$ Centre for Atmospheric Science, University of Cambridge, Cambridge, UK

${ }^{4}$ National Centre for Atmospheric Science, University of Cambridge, Cambridge, UK

${ }^{5}$ NASA Jet Propulsion Laboratory, Pasadena, California, USA

${ }^{6}$ National Center for Atmospheric Research, Boulder, Colorado, USA

${ }^{7}$ UCAR/NOAA Geophysical Fluid Dynamics Laboratory, Princeton, New Jersey, USA

${ }^{8}$ School of GeoSciences, University of Edinburgh, Edinburgh, UK

${ }^{9}$ Department of Physics, Imperial College, London, UK

${ }^{10}$ Lancaster Environment Centre, Lancaster University, Lancaster, UK

${ }^{11}$ Lawrence Livermore National Laboratory, Livermore, California, USA

${ }^{12}$ Agenzia nazionale per le nuove tecnologie, l'energia e lo sviluppo economico sostenibile (ENEA), Bologna, Italy

${ }^{13}$ Met Office Hadley Centre, Exeter, UK

${ }^{14}$ CICERO, Center for International Climate and Environmental Research-Oslo, Oslo, Norway

${ }^{15}$ Deutsches Zentrum für Luft- und Raumfahrt (DLR), Institut für Physik der Atmosphäre, Oberpfaffenhofen, Germany

${ }^{16}$ NASA Goddard Institute for Space Studies, and Columbia Earth Institute, Columbia University, New York City,

New York, USA

${ }^{17}$ NOAA Geophysical Fluid Dynamics Laboratory, Princeton, New Jersey, USA

${ }^{18}$ GAME/CNRM, Météo-France, CNRS - Centre National de Recherches Météorologiques, Toulouse, France

${ }^{19}$ Frontier Research Center for Global Change, Japan Marine Science and Technology Center, Yokohama, Japan

${ }^{20}$ Canadian Centre for Climate Modeling and Analysis, Environment Canada, Victoria, British Columbia, Canada

${ }^{21}$ NASA Goddard Space Flight Center, Greenbelt, Maryland, USA

${ }^{22}$ Universities Space Research Association, Columbia, Maryland, USA

${ }^{23}$ Department of Earth and Environmental Science, Graduate School of Environmental Studies, Nagoya University, Nagoya, Japan

${ }^{24}$ Laboratoire des Sciences du Climat et de l'Environnement, LSCE-CEA-CNRS-UVSQ, Gif-sur-Yvette, France

${ }^{25}$ National Institute of Water and Atmospheric Research, Lauder, New Zealand

* now at: Lancaster Environment Centre, Lancaster University, Lancaster, UK

** now at: Department of Meteorology, University of Reading, Reading, UK

Correspondence to: P. J. Young (paul.j.young@lancaster.ac.uk)

Received: 27 July 2012 - Published in Atmos. Chem. Phys. Discuss.: 22 August 2012

Revised: 1 February 2013 - Accepted: 12 February 2013 - Published: 21 February 2013 
Abstract. Present day tropospheric ozone and its changes between 1850 and 2100 are considered, analysing 15 global models that participated in the Atmospheric Chemistry and Climate Model Intercomparison Project (ACCMIP). The ensemble mean compares well against present day observations. The seasonal cycle correlates well, except for some locations in the tropical upper troposphere. Most $(75 \%)$ of the models are encompassed with a range of global mean tropospheric ozone column estimates from satellite data, but there is a suggestion of a high bias in the Northern Hemisphere and a low bias in the Southern Hemisphere, which could indicate deficiencies with the ozone precursor emissions. Compared to the present day ensemble mean tropospheric ozone burden of $337 \pm 23 \mathrm{Tg}$, the ensemble mean burden for 1850 time slice is $\sim 30 \%$ lower. Future changes were modelled using emissions and climate projections from four Representative Concentration Pathways (RCPs). Compared to 2000, the relative changes in the ensemble mean tropospheric ozone burden in 2030 (2100) for the different RCPs are: $-4 \%$ $(-16 \%)$ for RCP2.6, $2 \%(-7 \%)$ for RCP4.5, $1 \%(-9 \%)$ for RCP6.0, and 7\% (18\%) for RCP8.5. Model agreement on the magnitude of the change is greatest for larger changes. Reductions in most precursor emissions are common across the RCPs and drive ozone decreases in all but RCP8.5, where doubled methane and a 40-150\% greater stratospheric influx (estimated from a subset of models) increase ozone. While models with a high ozone burden for the present day also have high ozone burdens for the other time slices, no model consistently predicts large or small ozone changes; i.e. the magnitudes of the burdens and burden changes do not appear to be related simply, and the models are sensitive to emissions and climate changes in different ways. Spatial patterns of ozone changes are well correlated across most models, but are notably different for models without time evolving stratospheric ozone concentrations. A unified approach to ozone budget specifications and a rigorous investigation of the factors that drive tropospheric ozone is recommended to help future studies attribute ozone changes and inter-model differences more clearly.

\section{Introduction}

The Atmospheric Chemistry and Climate Model Intercomparison Project (ACCMIP) is designed to complement the climate model simulations being conducted for the Coupled Model Intercomparison Project (CMIP), Phase 5 (e.g. Taylor et al., 2012), and both will inform the Intergovernmental Panel on Climate Change (IPCC) Fifth Assessment Report (AR5). A primary goal of ACCMIP is to use its ensemble of tropospheric chemistry-climate models to investigate the evolution and distribution of short-lived, chemically-active climate forcing agents for a range of scenarios, a topic that is not investigated in such detail as part of CMIP5. Ozone in the troposphere is one such short-lived, chemically-active forcing agent, and, as it is both a pollutant and greenhouse gas, it straddles research communities concerned with air quality and climate. This study is concerned with quantifying the evolution and distribution of tropospheric ozone in the ACCMIP models, detailing the projected ozone changes since the pre-industrial period through to the end of the 21 st century, with a focus on where the projected changes from the ensemble are robust.

Ozone is not directly emitted and its abundance in the troposphere is determined from a balance of its budget terms: chemical production and influx from the stratosphere, versus chemical loss and deposition to the surface (e.g. Lelieveld and Dentener, 2000). The magnitudes of these terms are sensitive to the prevailing climate, and the levels and locations of ozone precursor emissions, such as nitrogen oxides (NO and $\mathrm{NO}_{2}$; referred to as $\mathrm{NO}_{\mathrm{x}}$ ), carbon monoxide (CO) and volatile organic compounds (VOCs), including methane (e.g. Wild, 2007). A number global model studies have explored how changes in these drivers could affect tropospheric ozone abundances, from the pre-industrial period to future projections (e.g. Johnson et al., 1999; Collins et al., 2003; Prather et al., 2003; Shindell et al., 2003, 2006c; Sudo et al., 2003; Zeng and Pyle, 2003; Mickley et al., 2004; Hauglustaine et al., 2005; Lamarque et al., 2005, 2011; Stevenson et al., 2005; Brasseur et al., 2006; Dentener et al., 2006; West et al., 2007; Wu et al., 2008; Zeng et al., 2008; Jacobson and Streets, 2009; Young et al., 2009; Kawase et al., 2011).

Estimates of past emissions of anthropogenic ozone precursors are much lower than for the present day (e.g. Lamarque et al., 2010), meaning models project large increases in tropospheric ozone since the pre-industrial era (Hauglustaine and Brasseur, 2001; Lamarque et al., 2005; Shindell et al., 2006a; Cionni et al., 2011). This is in qualitative agreement with observationally based assessments (Volz and Kley, 1988), although matching the estimated low surface ozone concentrations (Marenco et al., 1994; Pavelin et al., 1999) is challenging (Hauglustaine and Brasseur, 2001; Mickley et al., 2001). Future projections of anthropogenic ozone precursor emissions used by earlier model studies often relied on the high population/high fossil fuel growth scenarios of Nakicenovic et al. (2000), meaning large emission increases (e.g. $\mathrm{NO}_{\mathrm{x}}$ emissions increasing nearly 4 -fold between the 1990 and 2100), resulting in large increases in tropospheric ozone levels (Stevenson et al., 2000; Sudo et al., 2003; Zeng and Pyle, 2003; Shindell et al., 2006c). However, more recent emission projections have included scenarios with reductions in anthropogenic precursor emissions (considering more extensive air quality legislation), resulting in decreased tropospheric ozone compared to the present day (Dentener et al., 2005; Stevenson et al., 2006; West et al., 2006, 2007, 2012; Kawase et al., 2011; Lamarque et al., 2011). With regard to natural emissions, lightning $\mathrm{NO}_{\mathrm{x}}$ emissions have generally been thought to increase in a warmer climate (e.g. Price and Rind, 1994; Schumann and Huntrieser, 2007), although 
this result is not universal (Stevenson et al., 2005; Jacobson and Streets, 2009). For biogenic emissions, isoprene is likely the largest contributor (e.g. Guenther et al., 1995). At the leaf level, its emission flux depends on climate and (inversely) on $\mathrm{CO}_{2}$ concentration (Guenther et al., 2006; Arneth et al., 2010), and whether future isoprene emission is projected to increase (Sanderson et al., 2003; Lathièire et al., 2005) or decrease (Arneth et al., 2007a; Young et al., 2009) depends on whether the $\mathrm{CO}_{2}$ dependency is excluded or included (see also Pacifico et al., 2009). Biogenic emissions also depend on the amount and type of the vegetation, so projecting past and future emissions also depends on changes in vegetation growth, land cover and land use (Sanderson et al., 2003; Wiedinmyer et al., 2006; Arneth et al., 2008; Ashworth et al., 2012). These changes also impact deposition rates (Ganzeveld et al., 2010), all together making for complex biosphere-atmosphere interactions (Arneth et al., 2010).

The impacts of climate change on meteorology and largescale atmospheric dynamics are also important for tropospheric ozone. For example, several studies report an increase in the stratospheric influx of ozone in response to a warming climate, resulting from a climate change-driven strengthening of the residual circulation (Collins et al., 2003; Sudo et al., 2003; SPARC-CCMVal, 2010), coupled with the impact of higher-than-present levels of stratospheric ozone (Hegglin and Shepherd, 2009; Zeng et al., 2010). On the other hand, increases in specific humidity in a warmer atmosphere can increase the ozone loss rate, speeding up the reaction rate of $\mathrm{O}\left({ }^{1} \mathrm{D}\right)+\mathrm{H}_{2} \mathrm{O}$ (producing $\mathrm{OH}$ ) at the expense of collisional quenching, $\mathrm{O}\left({ }^{1} \mathrm{D}\right)+\mathrm{M}$ (producing ozone again) (Thompson et al., 1989; Johnson et al., 1999). Higher temperatures also reduce the efficacy of peroxy acetyl nitrate (PAN) as a $\mathrm{NO}_{\mathrm{x}}$ reservoir, and can mean larger or smaller rate coefficients, depending on the activation energy of the given reaction.

Despite general agreement on how the drivers impact global-scale shifts in tropospheric ozone, magnitudes of the regional changes and the overall ozone budget vary considerably between different models (Stevenson et al., 2006; Wild, 2007; Wu et al., 2007). With the movement to consider more physical processes and create complex Earth system models, uncertainty for future climate and composition projections may well increase (Stainforth et al., 2007). Yet, multi-model evaluation against present day observations and comparisons of the projections between models remains useful, both for benchmarking and for identifying consistent and contradictory results between different parameterisations (e.g. Dentener et al., 2006; Shindell et al., 2006b; Stevenson et al., 2006). In this study we analyse the multi-model ACCMIP ensemble ozone changes, from 1850 through to near- (2030) and further-term (2100) projections, using the latest set of scenarios developed for the CMIP5 simulations. This is the first study to examine the spread of modelled ozone responses using these scenarios, expanding the singlemodel studies of Kawase et al. (2011), Cionni et al. (2011) and Lamarque et al. (2011), and building on the last major multi-model model comparison for tropospheric ozone changes, coordinated by the European Union project Atmospheric Composition Change: the European Network of Excellence (ACCENT) (Stevenson et al., 2006). The main focus of this study is on the ensemble mean ozone change, and the robustness of the results across the ACCMIP ensemble. A detailed investigation into the "process-based" drivers of the ozone changes and inter-model differences is not possible due to the limited ozone budget data and the lack of simulations designed to isolate particular processes (e.g. as per Lee et al., 2012); we recommend that this is a priority for future chemistry-climate model comparisons. The analysis complements parallel investigation of the ACCMIP ensemble, related to climate evaluation (Lamarque et al., 2013), $\mathrm{OH}$ and methane lifetime (Naik et al., 2012; Voulgarakis et al., 2012), and the radiative impact of tropospheric ozone (Bowman et al., 2012; Shindell et al., 2012; Stevenson et al., 2012). This study is also complementary to an investigation of tropospheric and stratospheric ozone in the CMIP5 models (Eyring et al., 2012).

This study is organised as follows. Section 2 summarises the salient details of the ACCMIP models and the simulations analysed, followed by a comparison of the model emissions in Sect. 3. Section 4 discusses the present day distribution of tropospheric ozone and the inter-model differences, and presents a reference comparison of the models against a range of ozonesonde and satellite-based measurement data. The modelled ozone changes for the different scenarios are documented in Sect. 5, followed by a brief discussion of all the results in Sect. 6. Finally, Sect. 7 summarises the main conclusions and recommendations for future multi-model investigations of tropospheric ozone.

\section{Models, simulations and analysis details}

Here we provide brief details of the ACCMIP models and simulations, together with some details on the analysis performed in this study. Lamarque et al. (2013) provide a more complete description of the models, including appropriate references, and further details for the simulations.

\subsection{ACCMIP models}

Table 1 summarises the models, scenarios and their time periods analysed in this study (the tropospheric ozone burdens are discussed in later sections of the text). For this study, we used the output from 15 models, although not all of them provided output for every scenario and period, as indicated by "-" in Table 1 . Note that the analysis here does not include the ACCMIP model NCAR-CAM5.1 as this did not calculate ozone.

Most of the ACCMIP models are climate models with atmospheric chemistry modules, run in atmosphere-only 
Table 1. Tropospheric ozone burdens ( $\mathrm{Tg}$ ) for the individual models and the ACCMIP mean. Also shows which simulations and time slices are available from each model for this study. Not all relevant variables are available for each model/time slice.

\begin{tabular}{|c|c|c|c|c|c|c|c|c|c|c|c|}
\hline \multirow[t]{2}{*}{ Model } & \multicolumn{3}{|c|}{ Hist } & \multicolumn{2}{|c|}{ RCP2.6 } & \multicolumn{2}{|c|}{ RCP4.5 } & \multicolumn{2}{|c|}{ RCP6.0 } & \multicolumn{2}{|c|}{ RCP8.5 } \\
\hline & 1850 & 1980 & 2000 & 2030 & 2100 & 2030 & 2100 & 2030 & 2100 & 2030 & 2100 \\
\hline CESM-CAM-superfast & 192 & 288 & 302 & 278 & 230 & - & - & 289 & 252 & 328 & 384 \\
\hline CICERO-OsloCTM2 ${ }^{\mathrm{a}}$ & 206 & 287 & 308 & 296 & 247 & 312 & 274 & - & - & 326 & 343 \\
\hline CMAM & 239 & 310 & 323 & 307 & 266 & 330 & 293 & - & - & 342 & 371 \\
\hline EMAC & 259 & 352 & 378 & - & - & 379 & 342 & - & - & 399 & 441 \\
\hline GEOSCCM & 250 & 333 & 346 & - & - & - & - & - & - & - & - \\
\hline GFDL-AM3 & 264 & 370 & 378 & 367 & 317 & 389 & 356 & 390 & 359 & 410 & 484 \\
\hline GISS-E2-R ${ }^{b}$ & $252^{\mathrm{c}}$ & 337 & 344 & 341 & $304^{\mathrm{e}}$ & 352 & $321^{\mathrm{e}}$ & 352 & $339^{\mathrm{e}}$ & 379 & $417^{\mathrm{e}}$ \\
\hline GISS-E2-R-TOMAS & 261 & 350 & 359 & - & - & - & - & - & - & - & - \\
\hline HadGEM2 & 227 & 289 & 307 & 303 & 262 & 316 & 295 & - & - & 330 & 377 \\
\hline 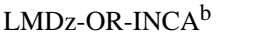 & $247^{\mathrm{c}}$ & 322 & $339^{d}$ & 321 & $278^{\mathrm{e}}$ & 342 & $310^{\mathrm{e}}$ & 329 & $306^{\mathrm{e}}$ & 351 & $374^{\mathrm{e}}$ \\
\hline MIROC-CHEM & 239 & 321 & 341 & 325 & 283 & - & - & 338 & 304 & 356 & 374 \\
\hline MOCAGE & 272 & 322 & 327 & 323 & 299 & - & - & 333 & 358 & 400 & \\
\hline NCAR-CAM3.5 & 221 & 318 & 336 & 317 & 263 & 336 & 294 & 322 & 285 & 349 & 386 \\
\hline STOC-HadAM3 & 234 & 332 & 348 & 329 & 272 & - & - & - & - & 367 & 385 \\
\hline UM-CAM & 226 & 304 & 322 & 323 & 293 & 338 & 322 & - & - & 351 & 397 \\
\hline Mean & 239 & 322 & 337 & 319 & 276 & 344 & 312 & 336 & 309 & 357 & 395 \\
\hline Sdev ( $\%$ of mean) & $22(9 \%)$ & $24(8 \%)$ & $23(7 \%)$ & $22(7 \%)$ & $25(9 \%)$ & $26(8 \%)$ & $26(8 \%)$ & $31(9 \%)$ & $35(11 \%)$ & $26(7 \%)$ & $36(9 \%)$ \\
\hline
\end{tabular}

a Simulations are a single year.

$\mathrm{b}$ These models submitted transient simulations. Their "time slice" means represent 10-yr averages about the given decade, except as noted.

c Mean of $1850-1859$.

d Mean of 1996-2000 (when the transient simulation stops)

e Mean of 2091-2100.

mode; i.e. the models are driven by sea-surface temperature (SST) and sea-ice concentrations (SICs). GISS-E2$\mathrm{R}$ uniquely was run as a fully coupled ocean-atmosphere climate model, although the closely related GISS-E2-RTOMAS model was run with SSTs and SICs prescribed. CICERO-OsloCTM2 and MOCAGE are chemical transport models (CTMs), with MOCAGE using offline meteorological fields from an appropriate simulation of a climate model, and CICERO-OsloCTM2 using offline meteorological fields from a single year of a reanalysis dataset. Except for the CTMs, and LMDz-OR-INCA, STOC-HadAM3 and UMCAM, the calculated ozone concentrations are used in the climate model radiation code, making most of the models chemistry-climate models (CCMs).

The model chemical schemes vary greatly in their complexity (e.g. as measured by the number of species and reactions), particularly in the range of non-methane VOCs (NMVOCs) that they simulate. Complexity ranges from the simplified and parameterized schemes of CMAM (no NMVOCs) and CESM-CAM-superfast (isoprene as the only NMVOC), to the intermediate schemes of HadGEM2 and UM-CAM (include $\leq \mathrm{C}_{3}$-alkanes), to the more complex schemes of the other models, which include the more reactive, chiefly anthropogenic NMVOCs (e.g. higher alkanes, alkenes and aromatic species), as well as lumped monoterpenes. Some representation of stratospheric chemistry is included in many models, with the exception of CICEROOsloCTM2, HadGEM2, LMDz-OR-INCA, STOC-HadAM3 and UM-CAM. CICERO-OsloCTM2 uses monthly-varying climatological ozone values from a previous model simulation (except for the lowest $\sim 2.5 \mathrm{~km}$ of the stratosphere), LMDz-OR-INCA uses a constant (in time) stratospheric ozone climatology (Li and Shine, 1995), whereas the other models without detailed stratospheric chemistry used the time varying stratospheric ozone dataset of Cionni et al. (2011).

\subsection{Scenarios and time slices}

The ACCMIP simulations broadly correspond with the CMIP5 scenarios (Taylor et al., 2012). Historical (hereafter Hist) simulations cover the preindustrial period to the present day, while a range of Representative Concentration Pathways (RCPs) (van Vuuren et al., 2011) cover 21st century projections. These latter scenarios are named for their nominal radiative forcing level (2100 compared to 1750 ), such that $\mathrm{RCP} 2.6$ corresponds to $2.6 \mathrm{Wm}^{-2}, \mathrm{RCP} 4.5$ to $4.5 \mathrm{Wm}^{-2}$, RCP6.0 to $6.0 \mathrm{Wm}^{-2}$ and RCP8.5 to $8.5 \mathrm{Wm}^{-2}$. Ozone precursor emissions from anthropogenic and biomass burning sources were taken from those compiled by Lamarque et al. (2010) for the Hist simulations, whereas emissions for the RCP simulations are described by Lamarque et al. (2013) (see also Lamarque et al., 2011; van Vuuren et al., 2011). Excluding methane emissions, all the RCPs include reductions and redistributions of ozone precursor emissions moving through the 21st century. Natural emissions, such as CO and VOCs from vegetation and oceans, and $\mathrm{NO}_{\mathrm{x}}$ from soils and lighting, were determined by each model group. The 
emissions used by the individual models are discussed further in Sect. 3.

With the exception of GISS-E2-R and LMDz-OR-INCA, each model conducted a set of time slice simulations for each scenario. In this study, we analyse output from the 1850 , 1980 and 2000 time slices from the Hist scenario, and the 2030 and 2100 time slices for the RCPs, to provide nearterm and longer-term perspectives. Except for the CTMs and GISS-E2-R, each model used climatological SSTs and SICs from coupled ocean-atmosphere CMIP5 simulations of a closely related climate model, typically averaged for the $10 \mathrm{yr}$ about each time slice (e.g. 2026-2035 for the 2030 time slice), although some models had interannually varying boundary conditions. CICERO-OsloCTM2 used the same meteorology for each simulation, whereas MOCAGE was run with meteorological fields from a climate model running the appropriate time slice and scenario, rather than directly using the SSTs and sea-ice to drive an atmosphere model. The number of years that the ACCMIP models simulated for each time slice mostly varied between 4 and $12 \mathrm{yr}$ for each model, although CICERO-OsloCTM2 only simulated a single year. However, as the boundary conditions (including biomass burning emissions) were constant for each year of a given time slice for most models, "interannual" variability is generally small (see Sect. 4).

GISS-E2-R and LMDz-OR-INCA both conducted transient simulations, and the data analysed in this study were averaged for the decade about each time slice (e.g. 19761985 for the 1980 time slice), with some minor exceptions as noted in Table 1.

\subsection{Analyses: tropopause definition and statistical definitions}

Throughout this analysis, the troposphere is defined as air with ozone concentrations less than or equal to $150 \mathrm{ppbv}$ (Prather et al., 2001), which is simple to employ and allows comparison against other model studies (e.g. Stevenson et al., 2006). For a consistent definition of the troposphere for all time slices, the definition is applied using the ozone from the Hist 1850 time slice mean, applied on a per model basis, and varying by month. We used the 1850 time slice to avoid issues with different degrees of stratospheric ozone depletion across the ensemble, particularly in the Southern Hemisphere (SH). While fixing the definition means we compare a consistent region of the atmosphere between different time slices, it does ignore the fact the tropopause height will likely alter with climate change (Santer et al., 2003a, b). Furthermore, values for the tropospheric ozone burdens and columns are obviously sensitive to the tropopause definition (Wild, 2007; Prather et al., 2011), and the differences generally amount to $\pm 5 \%$ compared to using the 2000 time slice mean ozone, although they can exceed $10 \%$ for a few models for the RCPs. We apply a pressure based tropopause definition to ensure a consistent comparison of the modelled tropospheric column ozone against satellite data in Sect. 4.2.

A statistical analysis of whether the projected ozone changes are significant against interannual variability is not possible with the ACCMIP data, mainly because the interannual variability is insufficiently characterised by the time slice runs, as most have constant SSTs and SICs on a yearto-year basis, and all have constant biomass burning emissions. Instead, we assess whether a given multi-model mean ozone change is significantly different from zero by using a paired sample Student's t test (e.g. Wilks, 2006). Changes are considered significant if the (absolute) mean change from all the models is greater than 2 times the standard error for the mean change (i.e. approximately the $5 \%$ level). One weakness of this analysis is that it cannot highlight regions where the models agree that the changes are not significant with respect to interannual variability (see Tebaldi et al., 2011).

For the most part, output from the models was interpolated to the grid used by Cionni et al. (2011), who compiled the ozone dataset recommended for use in the CMIP5 simulations $\left(5^{\circ}\right.$ by $5^{\circ}$ latitude/longitude and 24 pressure levels). However, the tropospheric burden and columns were calculated on a model's native grid.

\section{Emissions: differences and similarities between models}

While one goal of ACCMIP was for models to match each other's ozone precursor inputs as closely as possible, differences in model parameterisations and complexity means that some model diversity is unavoidable. In particular, natural emissions were not prescribed as part of the experimental design, and their differing treatment between models broadens the range of ozone precursors. Such differences are examples of why we need model comparisons.

Figure 1 shows the range in ozone precursor emissions in the ACCMIP models, presenting box-whisker plots for each scenario and time slice. The number of models that constitute the spread of the data is different for different simulations see Table 1. Tabulated emission data for the individual models can be found in Table S1 in the Supplement.

Figure 1a shows that the tropospheric methane burden is generally well constrained in the simulations, with the interquartile range (IQR) being 3-5.5\% of the mean burden. The close agreement is due to all models except LMDzOR-INCA having used prescribed methane surface concentrations for the Hist simulations, and only GISS-E2-R and LMDz-OR-INCA not prescribing concentrations for the RCP simulations. The methane burden approximately doubles from 1850 to 2000 , but 2100 burdens are $30 \%, 10 \%$ and $2.5 \%$ lower than 2000, for the RCP2.6, RCP4.5 and RCP6.0 scenarios respectively. For RCP8.5, by 2100 the methane burden has more than doubled again compared to 2000 . 
(a) Methane burden

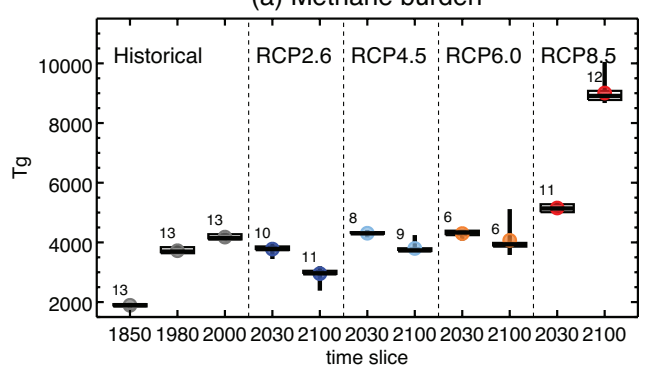

(b) $\mathrm{CO}$

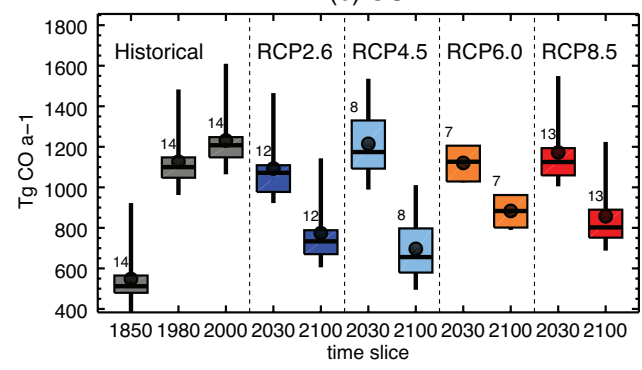

(c) Total NOx

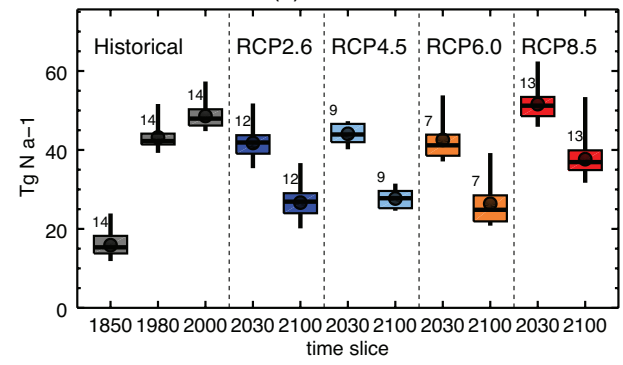

(d) LNOx

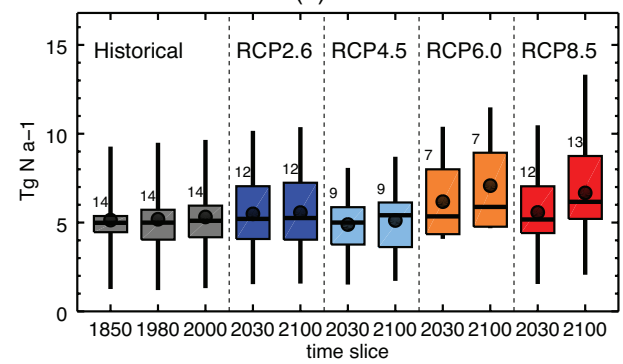

(e) Total VOC

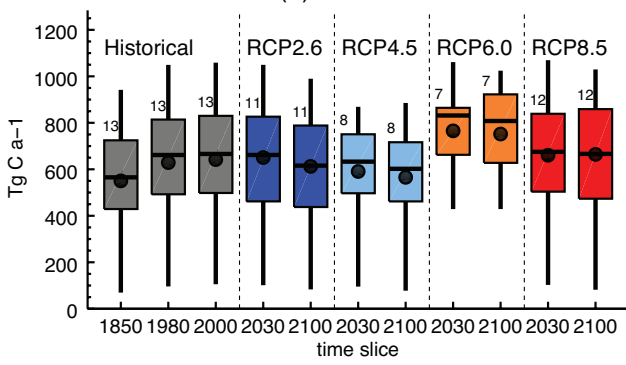

(f) Biogenic VOC

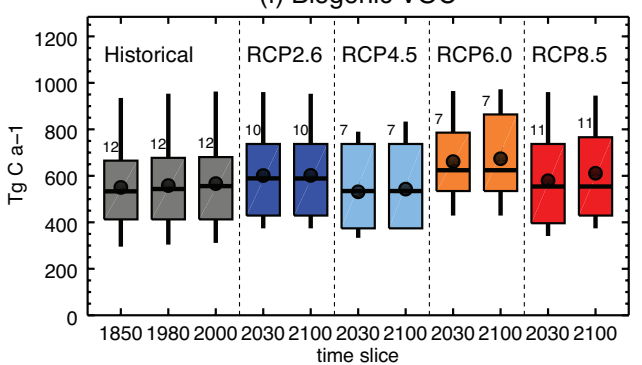

(g) Other VOC

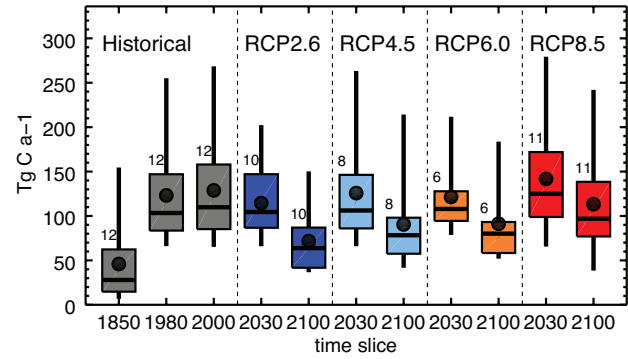

Fig. 1. Burdens and emissions of ozone precursors used in the ACCMIP scenarios and time slices, showing (a) the tropospheric methane burden, and yearly total (b) $\mathrm{CO}$ emissions, (c) total $\mathrm{NO}_{\mathrm{x}}$ emissions, (d) lightning $\mathrm{NO}_{\mathrm{x}}$ emissions and (e) total VOC emissions, which are then split into (f) biogenic VOCs and (g) other VOCs. The spread of the emissions/burden in each model is indicated for each scenario and time slice, with filled box showing the interquartile range, the whiskers indicating the full range, and the dot and line indicating the mean and median respectively. Not all models completed all the scenarios: the number of models used to determine each box/whisker is indicated.

The general trends in $\mathrm{CO}$ (Fig. 1b) and total $\mathrm{NO}_{\mathrm{x}}$ (Fig. 1c) emissions are similar, increasing from 1850 to 2000 for the Hist scenario, decreasing thereafter for all the RCPs, except for the $5 \%$ higher $\mathrm{NO}_{\mathrm{x}}$ emissions for the 2030 time slice of RCP8.5, compared to Hist 2000. $\mathrm{NO}_{\mathrm{x}}$ emissions show a stronger increase over the 20th century, with the mean trebling between 1850 and 2000, whereas CO emis- sions slightly more than double. Across all RCPs, by 2100 $\mathrm{CO}$ and $\mathrm{NO}_{\mathrm{x}}$ emissions are lower by $30-45 \%$ compared to 2000.

Both $\mathrm{CO}$ and $\mathrm{NO}_{\mathrm{x}}$ emissions show a greater degree of variation between the models than the methane burden. For a given time slice, the IQRs vary between approximately 10 $30 \%$ of the corresponding mean emission, whereas the full 
range (maximum minus minimum emission) is between 20 $100 \%$ of the mean emission. The spread is due to the varying natural emissions $\left(\mathrm{NO}_{\mathrm{x}}\right.$ from soils and lightning; $\mathrm{CO}$ from oceans and vegetation), as well as the less complex chemistry schemes used in some models including extra $\mathrm{CO}$ emissions as a surrogate for missing NMVOCs (e.g. CMAM, HadGEM2).

An example of the variation in natural emissions can be seen from Fig. 1d, which shows the spread in the lightning $\mathrm{NO}_{\mathrm{x}}$ source $\left(\mathrm{LNO}_{\mathrm{x}}\right)$ for the models. Parameterisations for $\mathrm{LNO}_{\mathrm{x}}$ are generally dependent on cloud top heights and convective mass fluxes (e.g. Price and Rind, 1992; Allen and Pickering, 2002), which likely show large variability between models, accounting for spread. The IQRs are generally $40-55 \%$ of the mean emission, and the full range is $90-170 \%$ of the mean. The maximum emissions come from the MIROC-CHEM, whose $\mathrm{LNO}_{\mathrm{x}}$ was set mistakenly high (by $60 \%$ ) in the ACCMIP simulations. The minimum emissions $\left(<2 \mathrm{Tg} \mathrm{N} \mathrm{yr}^{-1}\right)$ are generally from the HadGEM2 $\mathrm{LNO}_{\mathrm{x}}$ (who also mistakenly implemented $\mathrm{LNO}_{\mathrm{x}}$ ), although emissions are also low for CMAM for the RCP simulations. Our knowledge of $\mathrm{LNO}_{\mathrm{x}}$ is generally poor, but (excluding HadGEM2 and MIROC-CHEM) $\mathrm{LNO}_{\mathrm{x}}$ for the Hist 2000 simulation ranges between $3.8-7.7 \mathrm{Tg} \mathrm{N} \mathrm{yr}^{-1}$, within the range of $5 \pm 3 \mathrm{Tg} \mathrm{Nyr}^{-1}$ estimated by Schumann and Huntrieser (2007) for a range of $\mathrm{LNO}_{\mathrm{x}}$ parameterisations.

Possible changes in lightning activity with climate change (e.g. Williams, 2009 and refs. therein) have been recognised as potentially important for $\mathrm{LNO}_{\mathrm{x}}$ and the subsequent impact on tropospheric composition (e.g. Price and Rind, 1994; Hauglustaine et al., 2005; Fiore et al., 2006; Schumann and Huntrieser, 2007; Zeng et al., 2008), even if only the spatial distribution changes (Stevenson et al., 2005). An increase in $\mathrm{LNO}_{\mathrm{x}}$ from 2000 to 2100 (RCP8.5; strongest warming) is generally robust across the ACCMIP models, and ranges in magnitude from $10-75 \%$. CMAM is an outlier in this case, with $45 \%$ lower emissions for RCP8.5 2100 compared to Hist 2000. CMAM is also the only model using an $\mathrm{LNO}_{\mathrm{x}}$ parameterisation based on the study of Allen and Pickering (2002). Jacobson and Streets (2009) also modelled lower $\mathrm{LNO}_{\mathrm{x}}$ in a warmer climate, using a different parameterisation based on cloud ice. Clearly further study is required into the implications of the use of different parameterisations for $\mathrm{LNO}_{\mathrm{x}}$, and the different sensitivities across models.

Figure 1e shows the total VOC emissions used in the ACCMIP models. As with $\mathrm{LNO}_{\mathrm{x}}$, the emissions cover a wide range and there is no clear trend in the mean across the simulations. Many of the reasons for the differences are familiar from the above discussion, particularly the fact that some models include more VOC species than others. Another reason for the spread in VOC emissions comes from treatment of VOCs of biogenic origin, particularly isoprene, which likely dominates the total NMVOC emissions (e.g. Guenther et al., 1995). Figure if shows the spread of biogenic VOC emissions between the ACCMIP models; these emissions are mostly isoprene. EMAC, GEOSCCM, GISSE2-R and STOC-HadAM3 simulations were the only ones to include climate-sensitive isoprene emissions, and these are the only models with a positive change in VOC emissions between Hist 2000 and RCP8.5 2100, arising from the positive temperature dependence of isoprene emission algorithms (e.g. Guenther et al., 2006; Arneth et al., 2007b). Arneth et al. (2011) noted that the isoprene emission computed from a given algorithm is sensitive to the input meteorological data and vegetation boundary conditions, giving further cause for variation in VOC emissions between models. For the rest of the ACCMIP ensemble, if they included isoprene chemistry, constant present day isoprene emissions were used for all simulations. Figure $1 \mathrm{~g}$ shows that the trend in the nonbiogenic VOC emissions (anthropogenic plus biomass burning) broadly resembles that of $\mathrm{CO}$ and $\mathrm{NO}_{\mathrm{x}}$, albeit with the range of VOC complexity resulting in a larger spread of the emission total between the models (IQR is $30-100 \%$ of the mean emission).

\section{Present day ozone distribution and model-observation comparison}

This section presents the tropospheric ozone burden, the tropospheric ozone budget (for a limited subset of models), and the distribution of tropospheric ozone (surface, column and zonal mean) as simulated by the ACCMIP models for the Hist 2000 simulation. The ozone concentrations and columns from this simulation are then compared against observational datasets, from both satellites and ozonesondes. We do not over-interpret these comparisons since they exclude observational error, and they differ in the periods covered. The emphasis is largely on the distribution and measurement-model comparison for the ensemble mean, describing the spread of model results with statistical metrics. The distributions of ozone for all the individual models can be found in the supplementary material (Figs. S1-S3).

\subsection{Tropospheric ozone burden and budget}

Figure 2a shows the annual mean tropospheric ozone burden for all the models for Hist 2000, as well as the ACCMIP mean. Values for the tropospheric burden for all models and scenarios can also be found in Table 1. The mean burden is $337 \pm 23 \mathrm{Tg}$, very close to the $336 \pm 27 \mathrm{Tg}$ reported for a subset of the ACCENT models (Stevenson et al., 2006) ( $344 \pm 39 \mathrm{Tg}$ for the full ACCENT ensemble), and the $335 \pm 10 \mathrm{Tg}$ estimated from measurement climatologies by Wild (2007), although the latter estimate is from pre-2000 ozone data. Figure $2 \mathrm{a}$ also indicates the uncertainty in the ozone burden, as represented by the standard deviation of the range of burdens computed for individual years of the time slice. As might be expected from successive years of the same boundary conditions (for most models), the uncertainty 
Table 2. Tropospheric ozone budget statistics for a subset of ACCMIP models for the Hist 2000 time slice, showing chemical production $(\mathrm{P})$, chemical loss (L), deposition (D), the inferred stratospheric influx (S), and the lifetime $(\tau)$.

\begin{tabular}{lccccc}
\hline \multirow{2}{*}{ Model } & \multicolumn{4}{c}{ Flux terms/Tg ozone $\mathrm{a}^{-1}$} & \multirow{2}{*}{$\tau /$ days } \\
\cline { 2 - 5 } & $\mathrm{P}$ & $\mathrm{L}$ & $\mathrm{D}$ & $\mathrm{S}$ & \\
\hline CESM-CAM-superfast & 3877 & 3638 & 687 & 448 & 25.5 \\
GEOSCCM & 4692 & $3853^{*}$ & 1240 & 401 & 24.8 \\
GFDL-AM3 & 5853 & 5089 & 1240 & 476 & 21.8 \\
NCAR-CAM3.5 & 4494 & 4112 & 842 & 460 & 24.8 \\
STOC-HadAM3 & 5989 & 5050 & 1350 & 411 & 19.9 \\
UM-CAM & 4358 & 3816 & 1205 & 663 & 23.4 \\
\hline ACCENT mean (土 sdev) & $5110 \pm 606$ & $4668 \pm 727$ & $1003 \pm 200$ & $552 \pm 168$ & $22.3 \pm 2.0$ \\
\hline
\end{tabular}

* Loss flux includes wet deposition of oxidised nitrogen compounds.
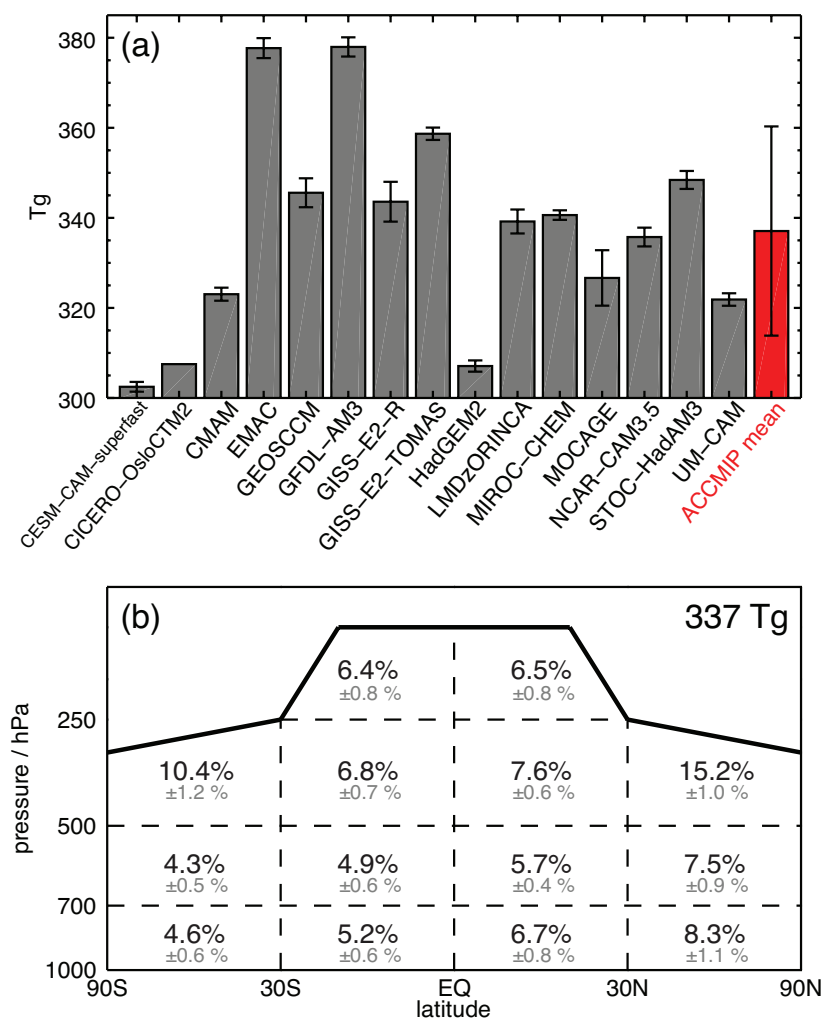

Fig. 2. (a) Tropospheric ozone burdens for the ACCMIP models from the Hist 2000 simulations. Error bars for the models indicate the variability in the burden between different years of a model's time slice ( \pm 1 std. dev.). The error bar on the ensemble mean burden indicates the inter-model spread of the burden ( \pm 1 std. dev.). (b) Distribution of the mean ozone burden throughout the troposphere for the mean model, using the "boxes" recommended by Lawrence et al. (2001) for reporting OH concentrations. The solid line indicates the tropopause (see text for definition). is small, and the standard deviations are less than $2 \%$ of the burden.

There is a significant correlation $(r=0.67)$ between the modelled ozone burden and the total VOC emissions. With the spread of VOC emission and treatment between the models, it is difficult to rationalise this correlation satisfactorily, although Wild (2007) demonstrated increased VOC emissions lead to an increased ozone burden. There is not a similar correlation between the ozone burden and total $\mathrm{NO}_{\mathrm{x}}$ emissions.

Figure $2 b$ indicates the distribution of the mean ozone burden throughout the troposphere, using the regions defined by Lawrence et al. (2001) (to describe the distribution of $\mathrm{OH}$ ) to give a mass-weighted view of the zonal ozone distribution. The hemispheric asymmetry in ozone is apparent from Fig. 2b, which shows that $57.5 \%$ of the ozone mass is in the NH. The NH extratropics has $60 \%$ more ozone than the $\mathrm{SH}$ extratropics overall, but the $\mathrm{NH}$ tropics has only slightly more ozone $(\sim 3 \%)$ than the SH tropics overall. The greatest burdens are found in the extratropical upper troposphere, reflecting the importance of stratosphere-to-troposphere transport of ozone. The next largest ozone burdens are found in the comparatively more polluted NH lower troposphere, as well as the tropical upper troposphere. This latter region is impacted by convective transport of ozone precursors and lightning emissions (Jacob et al., 1996). The standard deviation in the fractional distribution of ozone is also in Fig. 2b, showing that the model uncertainty in distribution of ozone mass is largest in the NH extratropics and in the upper troposphere in general, consistent with the results described in Sect. 4.2.

Table 2 presents the present day tropospheric ozone budget terms for the six models for which there are sufficient data. We do not report the ensemble mean result due to both the limited number of models and that the chemical production $(\mathrm{P})$ and loss $(\mathrm{L})$ terms were not calculated in a consistent manner (e.g. whether ozone loss through oxidised nitrogen species was considered); ozone dry deposition (D) was calculated consistently for these models however. Following Stevenson et al. (2006), the net influx of ozone from 
(a) Zonal mean conc (ppbv)

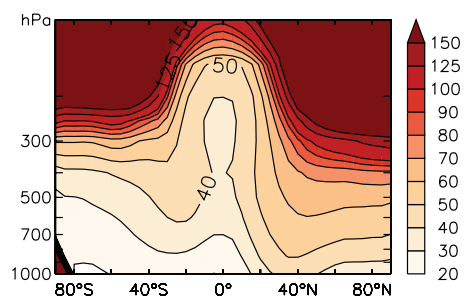

(d) Trop column (DU)

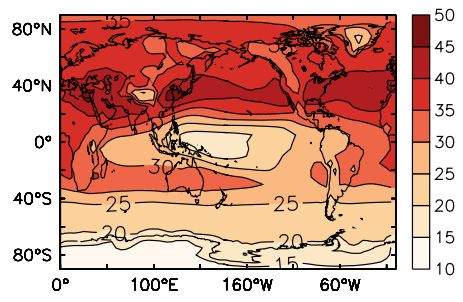

(g) Surface conc (ppbv)

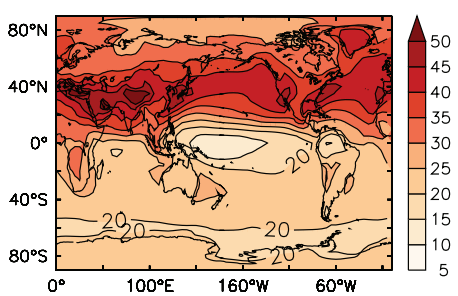

(b) Zonal mean sdev (ppbv)

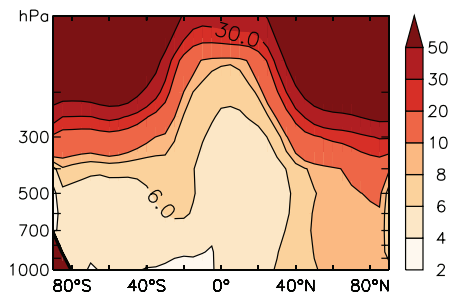

(e) Trop column sdev (DU)

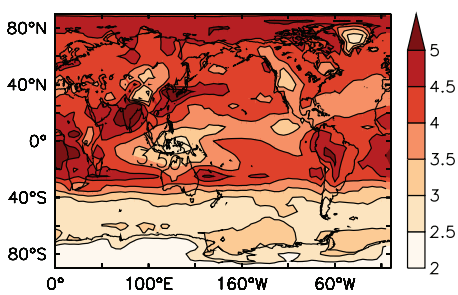

(h) Surface sdev (ppbv)

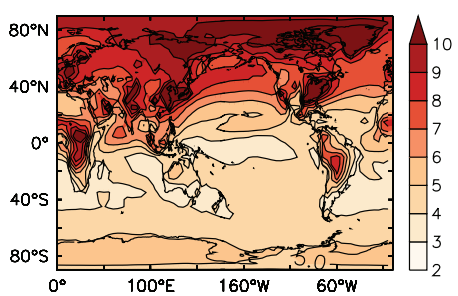

(c) Zonal mean sdev $(\%)$

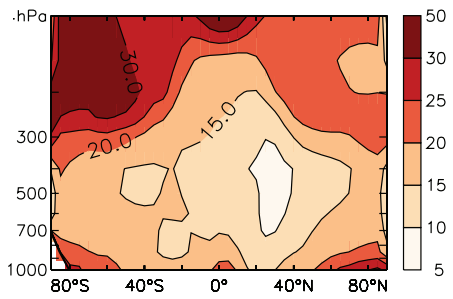

(f) Trop column sdev (\%)

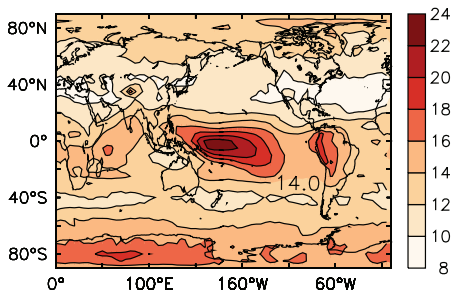

(i) Surface $\operatorname{sdev}(\%)$

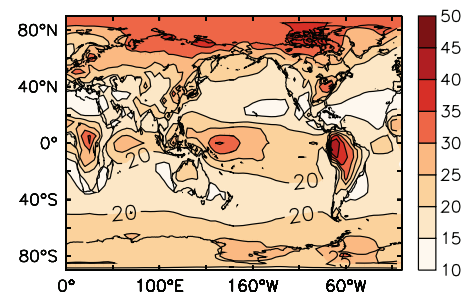

Fig. 3. ACCMIP ensemble mean, annual mean ozone climatologies and their inter-model variability, for the 2000 time slice of the Historical simulation. Top row shows zonal mean ozone, the middle row shows the tropospheric ozone column, and the bottom row shows surface ozone. For each row, the left hand panels show the absolute values of the ozone variable: ppbv for the zonal mean and surface concentrations, and Dobson units (DU) for the tropospheric column. The middle panels show the absolute standard deviations in the same units. The right hand column expresses the standard deviation as a percentage of the ensemble mean value (also known as the coefficient of variation). Note that each panel has a different scale.

the stratosphere $\left(S_{i n f}\right)$ is calculated from the residual of the other terms $\left(\mathrm{S}_{\mathrm{inf}}=\mathrm{P}-\mathrm{L}+\mathrm{D}\right)$, and the tropospheric ozone lifetime $(\tau)$ is calculated using the burdens $(\mathrm{B})$ in Table 1 ( $\tau=\mathrm{B} / \mathrm{F}$, where $\mathrm{F}=\mathrm{L}+\mathrm{D}=\mathrm{P}+\mathrm{S}_{\mathrm{inf}}$ ). As with the burden, all flux terms are defined using the $150 \mathrm{ppbv}$ ozone contour as the tropopause (from Hist 1850).

Several differences are apparent from comparing the ACCMIP results against the ACCENT study (the ACCENT mean data are shown in Table 2), although we caution that, with the limited amount of ACCMIP data, generalisations about how the modelled budget has changed since ACCENT are hard to make. For GFDL-AM3 and STOC-HadAM3, P is much higher than the ACCENT mean, whereas $\mathrm{P}$ is much lower for CESM-CAM-superfast, NCAR-CAM3.5 and UMCAM. For L, the ACCMIP models are broadly ordered the same as $\mathrm{P}$, although - unlike $\mathrm{P}$ - all the $\mathrm{L}$ terms all sit within the range described by the ACCENT mean and standard deviation. The ACCMIP models with the lower $\mathrm{P}$ and $\mathrm{L}$ have lower total VOC emissions (see Table S1b), which could go some way to explaining the range in Table 2 (e.g. Wild, 2007). These models also have the longest tropospheric ozone lifetimes. For D, the ACCMIP results span nearly a factor of two between CESM-CAM-superfast and STOCHadAM3. The fact that D does not simply correlate with $\mathrm{B}$ underlines that there are differences in the ozone spatial distribution and the deposition implementation between the models (see Lamarque et al., 2013), which has implications for assessing the impacts of ozone concentration changes on the biosphere (e.g. Sitch et al., 2007). For $S_{\text {inf }}$, all the ACCMIP models are encompassed by the ACCENT mean and standard deviation, and, furthermore, $\mathrm{S}_{\text {inf }}$ for the six models is within the $540 \pm 140 \mathrm{Tg} \mathrm{yr}^{-1}$ range suggested using observational constraints of stratosphere-to-troposhere exchange (Olsen et al., 2001; Wild, 2007). However, determining the net stratospheric influx by budget closure will likely give a different value to that calculated using transport diagnostics within the model (e.g. Sanderson et al., 2007), and - as with all the budget terms - there will be some sensitivity to the tropopause definition (Wild, 2007). 


\subsection{Zonal mean, tropospheric column and surface ozone from Hist 2000}

Figure 3 shows the ensemble mean, annual mean distribution of ozone, presenting the zonal mean, tropospheric column and surface ozone concentrations, as well as their intermodel variability. The general patterns of the ozone distribution in Figs. 3a, 3d and 3g are consistent with those reported from satellite (Fishman et al., 1990; Ziemke et al., 2011) and ozonesonde (Logan, 1999; Thompson et al., 2003) measurements, as well as the multi-model data shown by Stevenson et al. (2006). The increase in ozone concentration with height is clear, in accordance with the increase in ozone lifetime. Convective lifting of low-ozone air masses coupled with lofting of ozone precursors (Lawrence et al., 2003; Doherty et al., 2005) results in the characteristic tropical zonal mean profile in Fig. 3a. The hemispheric asymmetry in mid-tropospheric ozone concentrations reflects the larger input of stratospheric ozone in the NH, due to the stronger Brewer-Dobson circulation there (Rosenlof, 1995), as well as the larger emissions of ozone precursors (Lamarque et al., 2010). While both the tropospheric column (Fig. 3d) and surface concentrations (Fig. 3g) also show higher ozone levels over ozone precursor source regions, the plots also indicate enhanced concentrations downwind of the these regions, due to transport of ozone and ozone precursors, including "reservoir" species, such as PAN (Moxim et al., 1996; Fiore et al., 2009). Figure $3 \mathrm{~d}$ also shows the "wave-1" pattern in the tropical tropospheric ozone column (Thompson et al., 2003; Ziemke et al., 2011), with a minimum in ozone over the Pacific Ocean and maximum over the Atlantic. Surface ozone concentrations are also very low over the equatorial Pacific Ocean.

There is generally good agreement between the models for the zonal mean profile of ozone. Figure $3 \mathrm{c}$ shows that the standard deviation is less than $20 \%$ of the mean throughout much of the troposphere, with exception of some lower troposphere regions and the upper troposphere. The spatial patterns of the spread in surface ozone concentrations in Fig. 3h and i suggest that much of the lower troposphere variability is over regions with large anthropogenic, pyrogenic or biogenic emissions, where both the absolute and relative uncertainty is largest. In anthropogenic and biomass burning source regions, much of the model diversity could reflect the spread in VOC composition (low vs. high reactivity species), which means different ozone production efficiencies (e.g. Russell et al., 1995), as well as using different injection heights for biomass burning emissions. For tropical Africa and especially South America, large variations are apparent over isoprene source regions (surface and column), which reflects differences in the total emission (some models have no isoprene), as well as potentially differences in isoprene chemistry (Archibald et al., 2010).

Large model variation is also found for the high latitude $\mathrm{SH}$, chiefly for the tropospheric column. Tropospheric ozone levels in the $\mathrm{SH}$ are generally low, but there is relatively large diversity in the overhead stratospheric ozone column (standard deviation for the total ozone column is $10-15 \%$ of the mean; not shown). This results in a spread in the stratospheric input as well as potentially some impacts through changes in photolysis rates, for those models with photolysis schemes that use the model-calculated ozone column (e.g. Fuglestvedt et al., 1994; see also Voulgarakis et al., 2012). There is less (relative) variation in the tropospheric column in the Northern Hemisphere (NH), coupled with less spread between models for the total ozone column (not shown). But larger uncertainty for the surface at high latitudes could be related to differences in precursor transport and chemistry from lower latitudes (Eckhardt et al., 2003; Shindell et al., 2008; Christoudias et al., 2012). As was also found by Stevenson et al. (2006), there are large relative uncertainties in tropospheric column ozone over the equatorial Pacific Ocean, but the concentrations here are very low.

\subsection{Comparison to ozonesondes and satellite data}

Figure 4 compares the ACCMIP mean, median and individually modelled ozone concentrations from the Hist 2000 simulation against ozonesonde data, in the same manner as Stevenson et al. (2006). Ozonesonde measurements are taken from datasets described by Logan (1999) (representative of 1980-1993) and Thompson et al. (2003) (representative of 1997-2011), and consist of 48 stations, split 5, 15, 10 and 18 between the SH extratropics, SH tropics, NH tropics and NH extratropics respectively. The models were sampled at the ozonesonde locations. In addition, Fig. 4 shows satellite-derived ozone concentrations retrieved from the Tropospheric Emission Spectrometer (TES), which is a Fourier transform spectrometer on board the NASA Aura spacecraft in 2004 (Beer, 2006). TES ozone from a 2005-2010 climatology was interpolated to the same grid as the ACCMIP models and sampled at the ozonesonde locations. Figure 4 also shows the ACCENT model mean (Stevenson et al., 2006), to place the ACCMIP results in context of recent multi-model comparisons. The correlation and mean normalised bias error (MNBE) are shown for multi-model mean from the ACCMIP and ACCENT ensembles, relative to the ozonesonde observations.

Both the ACCMIP ensemble mean and median are within the standard deviation of the observations for most locations and altitudes, with the winter $\mathrm{NH}$ extratropical comparison being a notable exception. Indeed, compared to the mean observations, the largest relative errors are found for the NH extratropics, where the mean model overestimates the concentrations, and SH tropics, where the mean model underestimates the concentrations. The individual model biases in these locations are significantly correlated with total VOC emissions $(r=0.57$; i.e. more VOC emissions give a more positive, or less negative, bias), although several other chemical and transport factors likely play a role. However, the mean model captures the annual cycle 


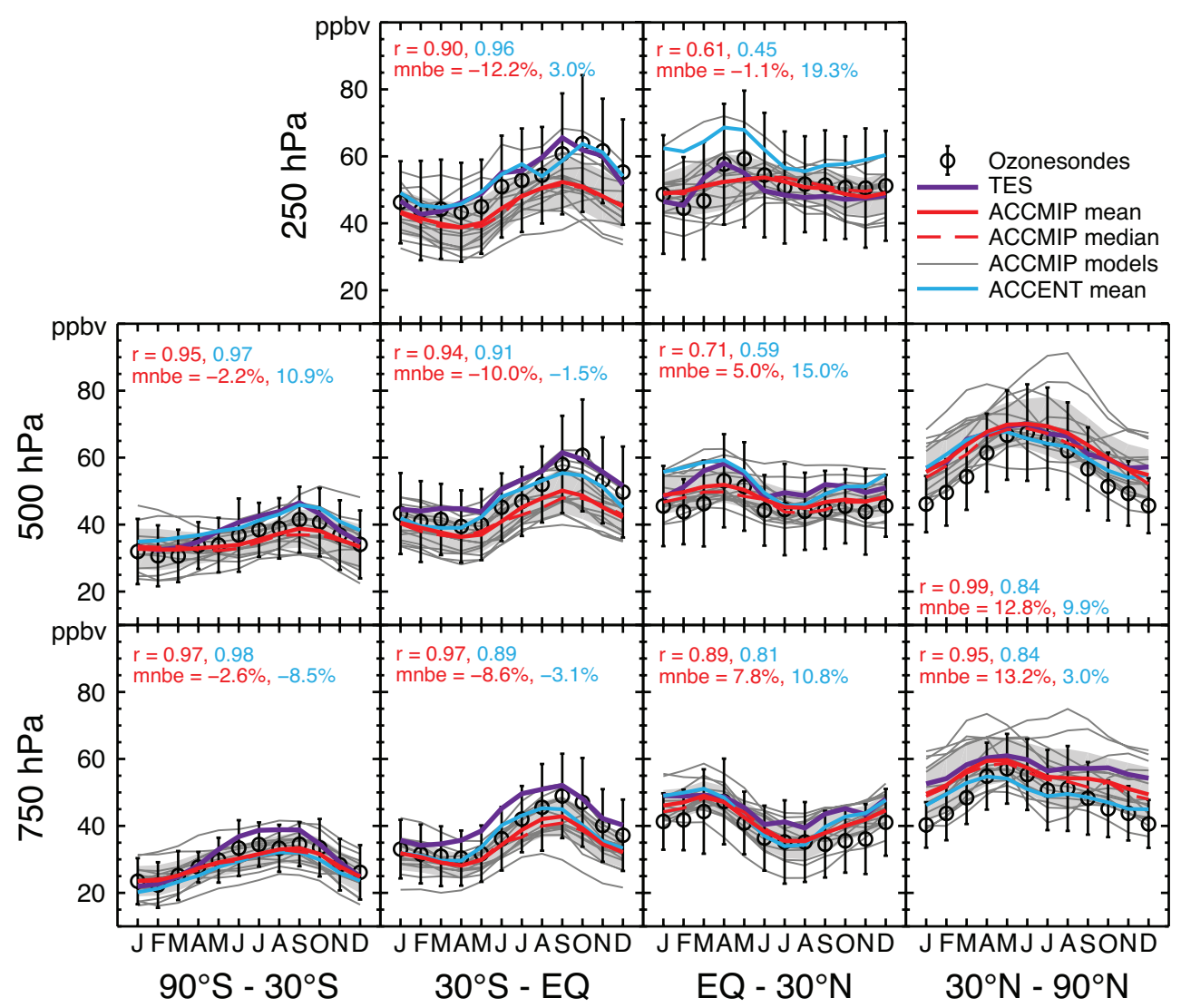

Fig. 4. Comparison of the annual cycle of ozone, between ozonesonde observations (black circles) and the ACCMIP ensemble mean (solid red line), ACCMIP ensemble median (dashed red line) and the ACCENT ensemble mean (blue line) (Stevenson et al., 2006). Ozone concentrations from TES (purple line) are also shown. ACCMIP model data is from the 2000 time slice mean of the Historical experiment. Model and observational data were grouped into four latitude bands $\left(90^{\circ} \mathrm{S}\right.$ to $30^{\circ} \mathrm{S}, 30^{\circ} \mathrm{S}$ to $0^{\circ}, 0^{\circ}$ to $30^{\circ} \mathrm{N}$ and $30^{\circ} \mathrm{N}$ to $\left.90^{\circ} \mathrm{N}\right)$ and sampled at three altitudes $(700 \mathrm{hPa}, 500 \mathrm{hPa}$ and $250 \mathrm{hPa})$, with the models sampled at the ozonesonde locations before averaging together. The individual ACCMIP models are represented by the thin grey lines, with the grey shaded area indicating \pm 1 standard deviation about the ACCMIP ensemble mean, showing the model spread. Error bars on the observations indicate the average interannual standard deviation for each group of stations. The correlation $(r)$ and mean normalised bias error (mnbe) for the ACCMIP (red) and ACCENT (blue) ensemble means versus the observations are also indicated in each panel. This figure is an update of Fig. 2 of Stevenson et al. (2006).

in ozone concentrations extremely well in most locations (as measured by the correlation coefficient), suggesting that, broadly speaking, the seasonality in circulation patterns, stratosphere-to-troposphere exchange and natural emissions (chiefly biomass burning in the tropics, and isoprene in the $\mathrm{NH}$ extratropics) is captured well. The statistics for the $\mathrm{NH}$ tropical mid and upper troposphere suggest that the seasonality is less well modelled, although we note that, (1) the observed-model correlation is significant $(r>0.58)$, (2) there is considerable observed interannual variability in ozone the upper troposphere, and (3) the bias and correlation are improved compared to the ACCENT mean. Compared to ACCENT, the correlation is improved with the ACCMIP mean model for most locations, and the bias for some locations, both most prominently in the NH.

Except for the NH Tropics at $250 \mathrm{hPa}$, the TES data are positively biased compared to the ozonesondes, broadly con- sistent with the 2-10 ppbv high bias that Nasser et al. (2008) noted for TES (see also Zhang et al., 2010). However, taking the interannual variability into account, and the fact that we have neither applied the TES operators in this analysis (Worden et al., 2007), nor considered measurement uncertainty, the TES and ozonesonde data are not notably different. This positive bias means that, compared to the ozonesonde data, the ACCMIP mean model bias against TES is improved for the NH extratropics, about the same for the NH tropics (opposite in sign), but worsened for the SH; changes in correlation compared to the ACCMIP-ozonesonde comparison are marginal. As mentioned above both the ozonesondes and TES see a sharp increase in ozone between March and April at EQ- $30^{\circ} \mathrm{N}$, not captured in the ACCMIP mean. TES (and several ACCMIP models) do not show the same low values in the winter months as the ozonesonde data. For TES, this is likely due to lower thermal contrast which will make the 

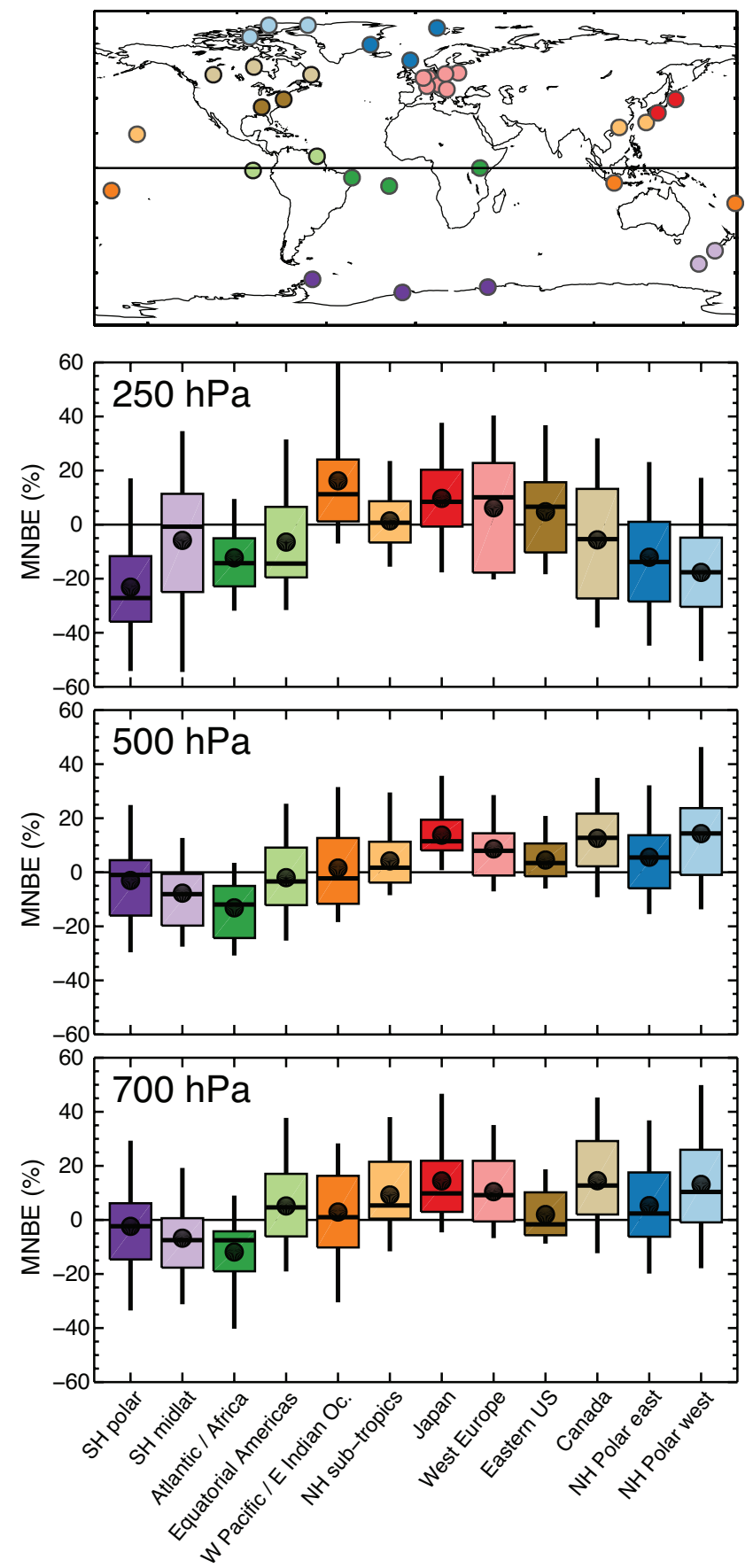

Fig. 5. Normalised biases for the ACCMIP models (Hist 2000 simulation) against the ozonesonde measurements compiled into regions by Tilmes et al. (2012). Each region is colour-coded, and the constituent ozonesonde sites are indicated in the top panel. Biases are shown for (bottom to top) 750,500 and $250 \mathrm{hPa}$. The box, whiskers, line and dot show the interquartile range, full range, median and mean biases respectively, in a similar style to Fig. 1 . The y-axis has the same scale in each panel. satellite retrievals relax to an a priori value (Bowman et al., 2006). Bowman et al. (2012) pursue comparisons of the ACCMIP models against TES further.

Figure 5 makes a similar comparison to ozonesonde data, this time using the compilation of Tilmes et al. (2012). This dataset mostly consists of the same station data described by Logan (1999) and Thompson et al. (2003), but covering 1995-2009, and aggregated into 12 regions that exhibit similar ozone concentration characteristics (see the top panel of Fig. 5 and Tilmes et al., 2012). The figure presents the mean, median and spread of the MNBE for the individual ACCMIP models (cf. Fig. 1), showing that the full range of performance encompasses positive and negative biases for each region and altitude.

The information in Fig. 5 is consistent with that in Fig. 4, but with more longitudinal information. For instance, we see that the negative bias in the SH tropical ozone is driven by the less favourable comparison of the model mean with the sites in the Atlantic/Africa region (dark green), and the sign of the bias is consistent across more than $75 \%$ of the models. A positive bias is apparent in all the $\mathrm{NH}$ extratropical regions in the low and mid-troposphere, and again is shared by the majority of the models. Figure 5 also shows low biases for the high latitude regions in the upper troposphere/lower stratosphere (UT/LS; a region not shown in Fig. 4). A comparison of the ACCMIP mean total ozone column against satellite measurements from the merged Total Ozone Mapping Spectrometer/solar backscatter ultraviolet (TOMS/SBUV) data (Stolarski and Frith, 2006) suggests that the models overestimate the total ozone column by around $5 \%$ at high latitudes (not shown), although the total column bias is not necessarily related to UT/LS biases. Validation of stratospheric ozone in these models is beyond the scope of this study, but this would help resolve whether ozonesondemodel comparisons at higher altitudes are consistent with the satellite data. (A comparison of the ensemble mean ozone column against TOMS data can be found in the supplementary material, along with a comparison of late twentieth century trends.)

Tropospheric ozone columns are available from a combination of the Ozone Monitoring Instrument (OMI) and Microwave Limb Sounder (MLS) data. Figure 6 compares the ACCMIP mean tropospheric column ozone against the OMIMLS climatology derived by Ziemke et al. (2011), covering October 2004 to December 2010. Tables 3 and 4 summarise the comparisons between the OMI/MLS data and individual models, showing the global $\left(60^{\circ} \mathrm{S}-60^{\circ} \mathrm{N}\right)$ column biases and spatial correlations, and biases by latitude bands respectively. For each model, the column was defined using the tropopause pressures provided by Ziemke et al. (2011) (from the National Centers for Environmental Prediction, NCEP), meaning that Fig. 6a is subtly different from Fig. 2d.

From Table 3, the global, ensemble mean tropospheric ozone column is $30.8 \mathrm{DU}$, compared to $31.1 \mathrm{DU}$ for OMI/MLS, although the latter has a root-mean square 
(a) ACCMIP ensemble (DU)

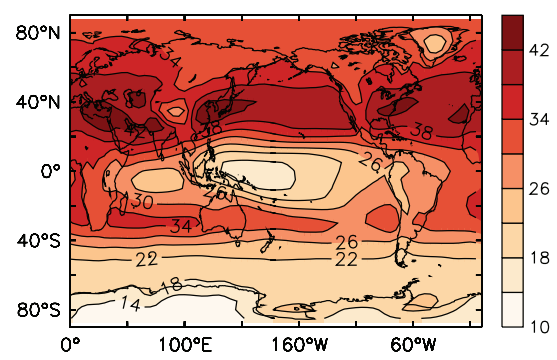

(b) OMI/MLS climatology (DU)

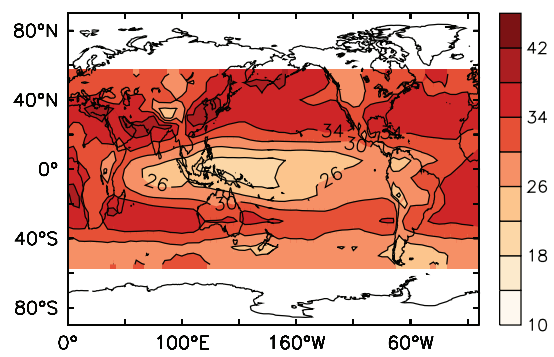

(c) ACCMIP - OMI/MLS (\%)

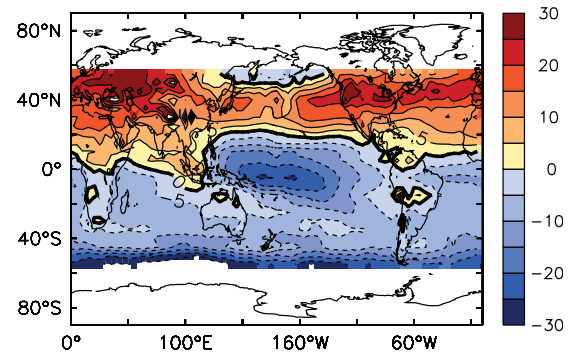

Fig. 6. Comparison of the annual mean tropospheric ozone column between (a) the ACCMIP ensemble (different tropopause compared to Fig. 2d) and (b) a climatology derived from the Ozone Monitoring Instrument (OMI) and Microwave Limb Sounder (MLS) by Ziemke et al. (2011). (c) ACCMIP ensemble bias compared to OMI/MLS (\%). See also Tables 2 and 3.

Table 3. Tropospheric ozone column, bias and spatial correation for the Hist 2000 simulation of the ACCMIP models vs. a climatology derived from OMI data (Ziemke et al., 2011).

\begin{tabular}{lcrc}
\hline Models & Column/DU & Bia/DU & $r$ \\
\hline CESM-CAM-superfast & 26.2 & -4.9 & 0.79 \\
CICERO-OsloCTM2 & 28.3 & -2.8 & 0.84 \\
CMAM & 30.3 & -0.8 & 0.87 \\
EMAC & 34.8 & 3.7 & 0.84 \\
GEOSCCM & 32.1 & 1.1 & 0.87 \\
GFDL-AM3 & 35.1 & 4.0 & 0.89 \\
GISS-E2-R & 33.7 & 2.6 & 0.85 \\
GISS-E2-R-TOMAS & 34.7 & 3.6 & 0.87 \\
HadGEM2 & 28.6 & -2.4 & 0.83 \\
LMDz-OR-INCA & 31.2 & 0.1 & 0.87 \\
MIROC-CHEM & 31.3 & 0.2 & 0.81 \\
MOCAGE & 28.8 & -2.2 & 0.60 \\
NCAR-CAM3.5 & 28.9 & -2.2 & 0.84 \\
STOC-HadAM3 & 28.7 & -2.4 & 0.81 \\
UM-CAM & 29.7 & -1.4 & 0.75 \\
\hline ACCMIP mean ( \pm sdev) & 30.8 & $-0.4 \pm 2.7$ & $0.87 \pm 0.07$ \\
\hline
\end{tabular}

interannual variability of $\sim 3 \mathrm{DU}$ (Ziemke et al., 2011), which overlaps an additional observationally-based estimate from the TES instrument of 29.8-32.8 DU (H. Worden, personal commnication, 2012). The range from these two instruments encompasses the columns calculated by $75 \%$ of the models. The spatial correlation between OMI/MLS and the models is generally very high (cf. Fig. 6a and b).

Many of the differences between the ensemble mean and OMI/MLS are broadly consistent with the comparison against ozonesonde data (Fig. 6c; Table 4), and biases in the mean column for a given latitude band are well correlated with those for the ozonesondes ( $r \geq 0.75$ for any pressure level). Compared to OMI/MLS, the ensemble mean overestimates the column across the NH mid-latitudes, and underestimates the column over tropical oceans and for all regions poleward of approximately $30^{\circ} \mathrm{S}$, although the underestimate is stronger than suggested by the ozonesonde data. The negative bias over the equatorial Pacific in Fig. 6c is not consistent with the ozonesonde comparison in Fig. 5, which suggests a neutral or positive bias for the mean model. However, this region is poorly represented by ozonesonde measurements. Correlations between the biases for the $\mathrm{NH}$ and $\mathrm{SH}$ tropical columns are strong $(r=0.88)$, suggesting that similar processes are operating in the regions, even if the sign of the bias is different between them (i.e. a model with a stronger positive NH tropical bias likely has a SH tropical bias that is either positive, or less negative than the ensemble mean).

Overall, compared to the ensemble of observations, the models may have a systematic high bias in the $\mathrm{NH}$, and a systematic low bias in the SH. As the emissions are broadly consistent across the ensemble, the prevalence of this bias could suggest they are deficient in some way, in either their amount or distribution, or both. However, the models all typically fall within the interannual variability of the observations.

\section{Tropospheric ozone from 1850 to 2100}

In this section we consider the changes in tropospheric ozone projected by the ACCMIP models for the past (1850 and 1980), as well as for the near (2030) and more distant (2100) future, using the range of RCPs. We begin by discussing global-scale changes, followed by regional changes, before considering the drivers of the change.

\subsection{Global-scale changes: tropospheric ozone burden}

Figure 7a shows the annual average tropospheric ozone burden for the ACCMIP models for all the simulations and time slices considered. Figure $7 \mathrm{~b}$ shows the difference in the tropospheric ozone burden compared to the Hist 2000 simulation. Data for individual models burdens and their differences can be found in Tables 1 and 5 respectively.

The evolution of the mean tropospheric burden in Fig. 7a shows a $25 \%$ increase between 1850 and 1980, and a $29 \%$ increase between 1850 and 2000 (very close to the results of Lamarque et al., 2005); the burden increases by $4 \%$ between 1980 and 2000. Future projections vary with the scenario. Compared to the mean 2000 burden of $337 \mathrm{Tg}$, the relative changes in the mean burdens for 2030 (2100) for the 
Table 4. Tropospheric ozone column and bias (DU) for the Hist 2000 simulation of the ACCMIP models vs. the OMI climatology for different latitude bands.

\begin{tabular}{lcrrrrrrr}
\hline & \multicolumn{2}{c}{$60^{\circ} \mathrm{S}-30^{\circ} \mathrm{S}$} & \multicolumn{2}{c}{$30^{\circ} \mathrm{S}-$ Eq. } & \multicolumn{2}{c}{ Eq. $-30^{\circ} \mathrm{N}$} & \multicolumn{2}{c}{$30^{\circ} \mathrm{N}-60^{\circ} \mathrm{N}$} \\
\cline { 2 - 9 } & $\mathrm{Col}$ & Bias & Col & Bias & Col & Bias & Col & Bias \\
\hline CESM-CAM-superfast & 21.9 & -7.8 & 21.6 & -8.4 & 26.0 & -5.0 & 37.2 & 3.1 \\
CICERO-OsloCTM2 & 22.1 & -7.6 & 27.5 & -2.5 & 30.0 & -1.0 & 33.2 & -0.9 \\
CMAM & 29.1 & -0.6 & 27.5 & -2.4 & 29.3 & -1.7 & 36.5 & 2.4 \\
EMAC & 29.4 & -0.3 & 33.9 & 3.9 & 36.7 & 5.7 & 38.6 & 4.5 \\
GEOSCCM & 28.4 & -1.3 & 28.8 & -1.2 & 32.0 & 1.0 & 40.6 & 6.5 \\
GFDL-AM3 & 31.4 & 1.7 & 31.8 & 1.9 & 35.2 & 4.2 & 42.9 & 8.8 \\
GISS-E2-R & 27.4 & -2.3 & 29.0 & -1.0 & 33.5 & 2.5 & 46.5 & 12.4 \\
GISS-E2-R-TOMAS & 30.0 & 0.2 & 30.5 & 0.5 & 33.8 & 2.8 & 46.3 & 12.2 \\
HadGEM2 & 22.8 & -6.9 & 26.4 & -3.6 & 31.1 & 0.1 & 34.2 & 0.1 \\
LMDz-OR-INCA & 25.7 & -4.0 & 29.2 & -0.8 & 31.9 & 0.9 & 38.3 & 4.2 \\
MIROC-CHEM & 25.1 & -4.6 & 31.4 & 1.4 & 33.8 & 2.7 & 34.1 & -0.0 \\
MOCAGE & 18.9 & -10.8 & 24.5 & -5.5 & 32.3 & 1.3 & 40.0 & 5.9 \\
NCAR-CAM3.5 & 25.1 & -4.7 & 24.7 & -5.3 & 29.4 & -1.6 & 37.6 & 3.6 \\
STOC-HadAM3 & 21.5 & -8.3 & 26.1 & -3.8 & 31.2 & 0.2 & 35.8 & 1.7 \\
UM-CAM & 26.2 & -3.5 & 23.8 & -6.1 & 30.4 & -0.6 & 40.4 & 6.3 \\
\hline ACCMIP mean ( \pm sdev) & $25.7 \pm 3.7$ & -4.1 & $27.8 \pm 3.4$ & -2.2 & $31.8 \pm 2.7$ & 0.8 & $38.8 \pm 4.1$ & 4.7 \\
\hline OMI (obs) & 29.7 & & 30.0 & & 31.0 & & 34.1
\end{tabular}

Table 5. Differences in the tropospheric ozone burden compared to Hist 2000, using data in Table 1.

\begin{tabular}{|c|c|c|c|c|c|c|c|c|c|c|}
\hline \multirow[t]{2}{*}{ Model } & \multicolumn{2}{|c|}{ Hist } & \multicolumn{2}{|c|}{ RCP2.6 } & \multicolumn{2}{|c|}{ RCP4.5 } & \multicolumn{2}{|c|}{ RCP6.0 } & \multicolumn{2}{|c|}{ RCP8.5 } \\
\hline & 1850 & 1980 & 2030 & 2100 & 2030 & 2100 & 2030 & 2100 & 2030 & 2100 \\
\hline CESM-CAM-superfast & -111 & -14 & -24 & -72 & - & - & -14 & -51 & 26 & 82 \\
\hline CICERO-OsloCTM2 $2^{\mathrm{a}}$ & -102 & -20 & -11 & -61 & 5 & -34 & - & - & 18 & 36 \\
\hline CMAM & -84 & -13 & -16 & -57 & 7 & -30 & - & - & 19 & 48 \\
\hline EMAC & -118 & -25 & - & - & 1 & -36 & - & - & 22 & 63 \\
\hline GEOSCCM & -96 & -13 & - & - & - & - & - & - & - & - \\
\hline GFDL-AM3 & -114 & -8 & -11 & -61 & 11 & -22 & 12 & -19 & 32 & 106 \\
\hline GISS-E2-R & -92 & -7 & -3 & -40 & 9 & -23 & 8 & -5 & 35 & 74 \\
\hline GISS-E2-R-TOMAS & -98 & -8 & - & - & - & - & - & - & - & - \\
\hline HadGEM2 & -81 & -18 & -4 & -45 & 9 & -12 & - & - & 23 & 70 \\
\hline LMDz-OR-INCA & -92 & -17 & -18 & -61 & 2 & -29 & -11 & -33 & 12 & 35 \\
\hline MIROC-CHEM & -101 & -20 & -16 & -57 & - & - & -3 & -37 & 16 & 33 \\
\hline MOCAGE & -55 & -4 & -3 & -28 & - & - & 7 & -9 & 32 & 74 \\
\hline NCAR-CAM3.5 & -114 & -18 & -19 & -72 & 0 & -42 & -14 & -51 & 13 & 50 \\
\hline STOC-HadAM3 & -115 & -16 & -19 & -77 & - & - & - & - & 19 & 36 \\
\hline UM-CAM & -96 & -18 & 1 & -28 & 16 & 1 & - & - & 29 & 75 \\
\hline Mean & -98 & -15 & -12 & -55 & 7 & -25 & -2 & -29 & 23 & 60 \\
\hline $\operatorname{Sdev}(\%$ of mean) & $17(17 \%)$ & $6(39 \%)$ & $8(66 \%)$ & $16(30 \%)$ & $5(77 \%)$ & $13(52 \%)$ & $11(554 \%)$ & $19(65 \%)$ & $7(33 \%)$ & $22(37 \%)$ \\
\hline
\end{tabular}

different RCPs are: $-4 \%(-16 \%)$ for RCP2.6, $2 \%(-7 \%)$ for RCP4.5, $-1 \%$ ( $-9 \%)$ for RCP6.0, and $7 \%$ (18\%) for RCP8.5. RCP8.5 is the only scenario to show an ozone increase for both time slices $(23 \mathrm{Tg}$ and $60 \mathrm{Tg}$ ), whereas RCP4.5 shows an increase in 2030 ( $7 \mathrm{Tg})$, before decreasing in $2100(-25 \mathrm{Tg})$. The ozone burden for the 2030 time slice of RCP6.0 is unchanged compared to 2000, although it is still higher than 1980.

Figure 7 also shows a large range in the modelled ozone burdens and their differences, with overlapping IQRs be- tween many of the time slices. There is a good, but not perfect, correlation $(r>0.7)$ between the modelled ozone burden for Hist 2000 and that of other time slices (i.e. models generally simulate consistently high or low burdens). However, there is no correlation between the modelled ozone burden and a given burden change, nor between the changes in ozone burden for any two periods; i.e. there are no models that consistently simulate large (or small) ozone changes between time slices, at least at the global scale. This key result shows that models are sensitive to emissions and 

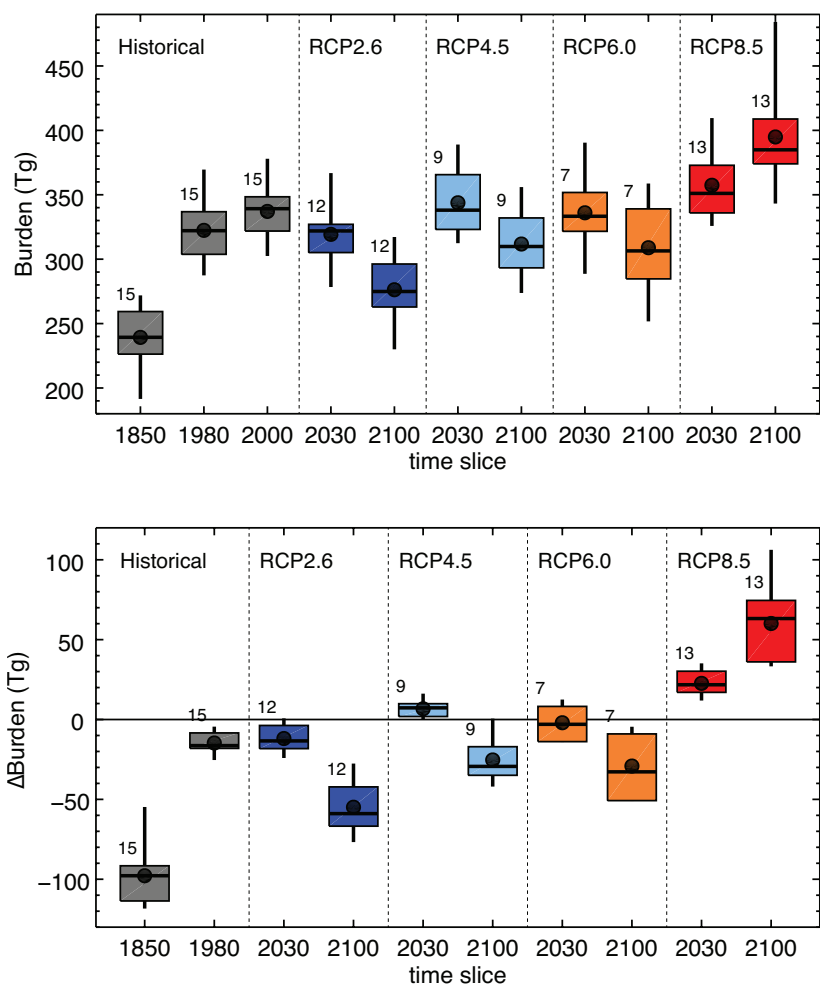

Fig. 7. (a) Modelled tropospheric ozone burdens for the different scenarios and time slices. (b) Change in the tropospheric burden, relative to the Hist 2000 simulation. The box, whiskers, line and dot show the interquartile range, full range, median and mean burdens and differences, and the numbers indicate the number of ACCMIP models with results for a given scenario and time slice, all in a similar style to Fig. 1.

climate changes in different ways. Furthermore, it suggests that model weighting schemes based on model skill (e.g. versus OMI-MLS) will not necessarily reduce the model spread for future projections. A deeper investigation into the drivers of this result requires more process-level information from the models (e.g. tropospheric ozone budgets from all models), and is not possible here.

The significance of the burden change with respect to Hist 2000 can also be assessed, using the inter-model spread of the differences (Sect. 2.3). This analysis suggests that all the changes in the ozone burden are significantly different from zero at the $5 \%$ level, except for between Hist 2000 and RCP6.0 2030, which is anticipated from Fig. 7b, as this is the only time slice where the models do not agree on the sign of the change. We again note that "significance" here does not mean that the change is significant with respect to interannual variability, merely a measure of whether the models agree on a change. As shown by Table 5, agreement between models on the magnitude of the burden change is generally better for the larger changes, namely Hist 1850, RCP2.6 2100, RCP8.5 2030 and RCP8.5 2100, where, as a percentage of the mean change, the standard deviation is $17 \%, 30 \%, 33 \%$ and $37 \%$ respectively. The standard deviations in the differences for the other scenarios vary between $40-80 \%$, although it is very large for RCP6.0 2030.

\subsection{Regional-scale changes: burdens, columns and concentrations}

Figure 8 shows the mean model regional ozone burden changes relative to Hist 2000 for the Hist 1850 and the four RCP 2100 simulations, dividing up the troposphere in the same manner as Fig. 3b. The figure also indicates the fraction that each region contributes to the overall ozone change, i.e. highlighting asymmetries in the change. From Fig. 7, we see that the overall ozone burden change is negative for all of these simulations, except RCP8.5 2100. Based on the spread of model results, all of the regional burden changes are significantly different from zero.

For Hist 1850 and RCP2.6 2100 the burden change is negative for all regions, with the largest contribution to the change coming from the lower ozone precursor emissions in the NH extratropics compared to Hist 2000. Unlike for the other RCPs, stratospheric ozone recovery (e.g. Eyring et al., 2010) does not force an increase in tropospheric ozone for the SH upper troposphere, despite a $30 \%$ increase in the total column ozone (not shown). However, an increase in stratospheric influx is likely masking what would otherwise be stronger negative changes due to the precursor decreases (see Sect. 5.3). The SH extratropics makes a small contribution to the overall change for both the Hist 1850 and RCP2.6 2100 case.

The overall decrease for RCP4.5 2100 is about half of that between RCP2.6 2100 and Hist 2000, but is still largely dominated by the decrease in precursor emissions in the $\mathrm{NH}$ extratropics, with some contribution from the $\mathrm{NH}$ tropical lower troposphere. This overall decrease is countered by a relatively large increase in the $\mathrm{SH}$ upper troposphere, likely related to ozone recovery. The magnitude and patterns of absolute ozone changes are similar for RCP6.0, although the tropical upper troposphere makes more of a contribution to the overall change than in RCP4.5, in both absolute and relative terms. For RCP8.5, ozone increases everywhere, although the largest contribution is from the 500 to $250 \mathrm{hPa}$ pressure band.

Figures 9, 10 and 11 present information on the annual mean spatial patterns of ozone concentration changes, relative to Hist 2000, for all the time slices, showing the absolute changes in zonal mean ozone, the tropospheric ozone column and surface ozone, respectively. Corresponding ozone differences for the individual models can be found in the Supplement (Figs. S4-S6).

Concentrations for Hist 1850 are less than Hist $2000 \mathrm{ev}$ erywhere except the stratosphere (Fig. 9a), showing the impact of increased precursors (Fig. 1) and CFC-induced ozone depletion respectively. Relative decreases exceed $40 \%$ for the column (Fig. 10a) and surface for $\mathrm{NH}$ mid-latitudes 

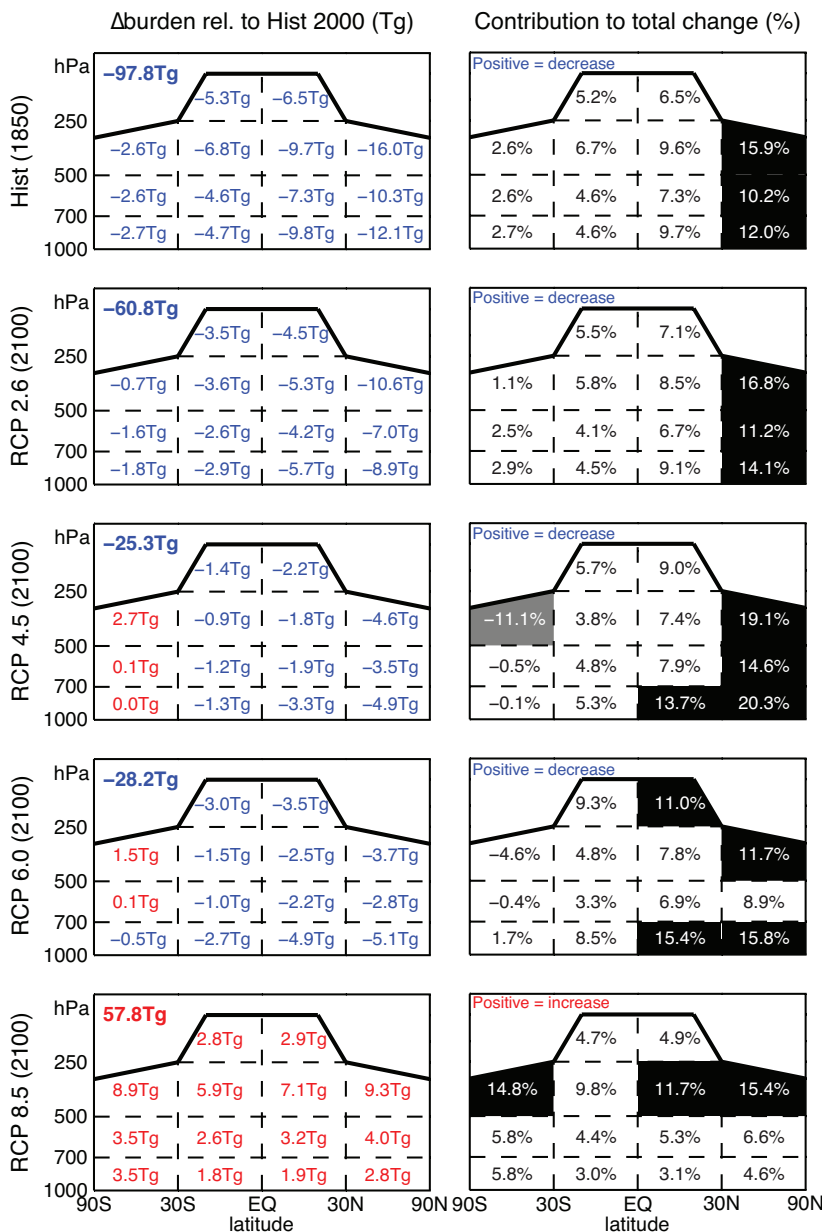

Fig. 8. ACCMIP ensemble mean change in the tropospheric ozone burden relative to the Hist 2000 simulation viewed in Lawrence et al. (2001)-style boxes (see also Fig. 3b), for (top to bottom) the Hist 1850, RCP2.6 2100, RCP4.5 2100, RCP6.0 2100 and RCP8.5 2100 simulations. The left hand column shows the absolute difference in ozone burden for the different boxes (red/blue for increase/decrease), with the tropospheric total change indicated in top left of each panel. The right hand column shows the fractional (\%) contribution of each box to the overall change in the tropospheric burden. A positive value indicates that the box's change is the same sign as the overall change. Boxes with a fraction larger than $10 \%$ are highlighted.

(Fig. 11a). For the latter, absolute decreases are $>25 \mathrm{ppbv}$ for the Mediterranean, much of Asia, and the western USA due to less precursor emissions. Differences between Hist 1980 and Hist 2000 are also significant in many parts of the atmosphere. These are distributed in a qualitatively similar manner to the Hist 1850 differences, but with smaller decreases due to the smaller change in precursor emissions, although the lower surface concentrations over South and East Asia highlight the recent emission growth in that region (e.g. Zhang et al., 2009). A notable non-significant change is seen for surface ozone concentrations over the eastern US, where $\sim 50 \%$ of the models simulate higher ozone for 1980 . This is in qualitative agreement with the recent analysis of ozone trends by Parrish et al. (2012), although transient simulations, better constrained to observed interannual changes in meteorology and emissions would be needed to investigate this further.

For RCP2.6, the distribution of tropospheric ozone changes is very similar to the Hist 1850 difference, with peak reductions of $30-40 \%$ by 2100 (Figs. $9 \mathrm{c}, 10 \mathrm{c}$ and $11 \mathrm{c}$ ) reflecting the partial reversal of the anthropogenic ozone precursor changes compared to 1850 and 2000. Similar patterns are evident again for RCP4.5 and RCP6.0 in 2100 (Fig. 9f and h), although (non-significant) increases in $\mathrm{SH}$ ozone penetrate deeper into the troposphere compared to RCP2.6 (see below). RCP4.5 also shows significant increases throughout the tropical and SH troposphere for the 2030 time slice (Fig. 9e), reflecting a redistribution in precursor emissions: tropical $\mathrm{NO}_{\mathrm{x}}$ emissions are higher for this scenario in 2030 than all others, except RCP8.5. Despite non-significant changes in the ozone burden for RCP6.0 2030 (Fig. 7), there are significant decreases in ozone in the tropical regions (Fig. 9f). RCP8.5 has significant increases throughout the troposphere, except for surface concentrations and the column over the equatorial Pacific in 2100, where the dominant effect may be increased specific humidity in the warmer climate increasing the ozone loss rate (e.g. Johnson et al., 1999; Zeng and Pyle, 2003).

The zonal mean ozone changes by 2100 for the different RCPs are qualitatively similar to those presented by Kawase et al. (2011), except that the ACCMIP ensemble mean does not show upper tropospheric ozone increases in the NH midlatitudes for RCP4.5 and 6.0. Sensitivity experiments by Kawase et al. (2011) demonstrated the importance of an enhanced Brewer-Dobson circulation (BDC) and recovery of stratospheric ozone levels in increasing future upper tropospheric ozone levels for RCP4.5, 6.0 and 8.5 in 2100. Stratospheric chemistry-climate models are robust in projecting recovery of the ozone layer due to a reduction in halogen levels (Eyring et al., 2010), as well as an intensification of the BDC with increased greenhouse gas concentrations (Butchart et al., 2006). The change in zonal mean ozone in Fig. 9 is characteristic of these processes, and, in particular, the reduction in tropical lower stratospheric ozone and enhancement of high latitude ozone is indicative of stronger BDC (Randel et al., 2002). This tropical/high-latitude seesaw pattern of the changes intensifies with the increased climate change from RCP2.6 to 8.5, further illustrating the coupling of the BDC to greenhouse gas levels in these models (see also Lamarque et al., 2011). The mid-latitude peaks in the tropospheric ozone column changes (Fig. 10j) are also indicative of increases in the stratospheric ozone influx (Olsen et al., 2004). For RCP8.5, the simulations of Kawase et al. (2011) also showed that the very large increase in methane levels was driving increases throughout most of the troposphere (see also Brasseur et al., 2006; Fiore et al., 2008). 
(a) Hist 1850

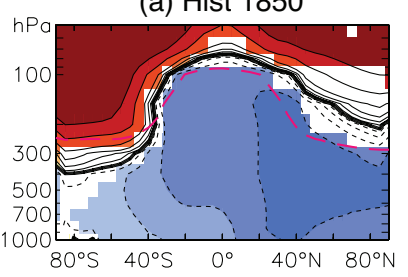

(c) RCP2.6 2030

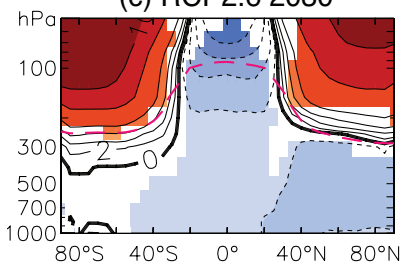

(e) RCP4.5 2030

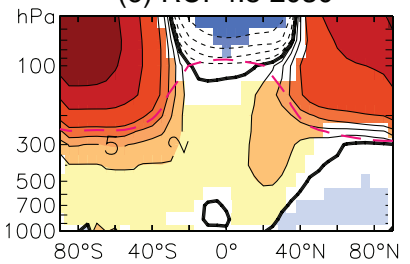

(g) RCP6.0 2030

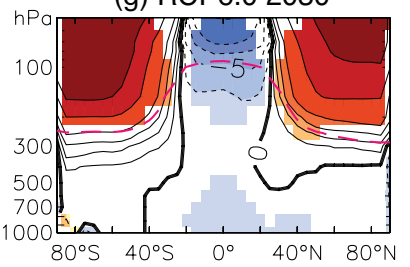

(i) RCP8.5 2030

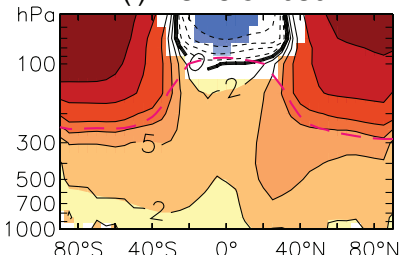

$40^{\circ} \mathrm{S}-0^{\circ}-40^{\circ} \mathrm{N} 80^{\circ} \mathrm{N}$

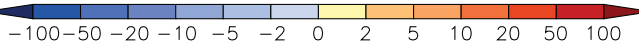

$\Delta \mathrm{O}_{3}(\mathrm{ZM}) / \mathrm{ppbv}$

Fig. 9. Absolute change in annual zonal mean ozone for the ACCMIP ensemble mean compared to the Hist 2000 simulation (ppbv). Top row shows the difference for the Hist 1850 and 1980 time slices. The next four rows show the difference for the 2030 and 2100 time slices of the RCP simulations. Non-white regions indicate where the change is significant at the $5 \%$ level, based on the spread of the differences between the models. The red dashed line indicates the position of the annual zonal mean $150 \mathrm{ppbv}$ ozone contour from the Hist 1850 simulation.

With the exception of the upper troposphere and lower stratosphere, the ozone differences in regions with nonsignificant changes are small, and it may be that the models agree that these changes in these regions are not significant in the context of interannual variability (Tebaldi et al., (a) Hist 1850

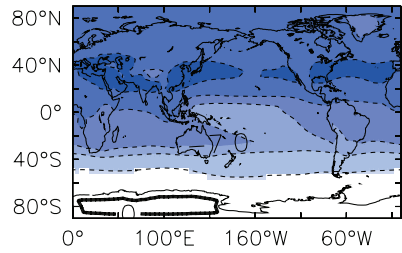

(c) RCP2.6 2030

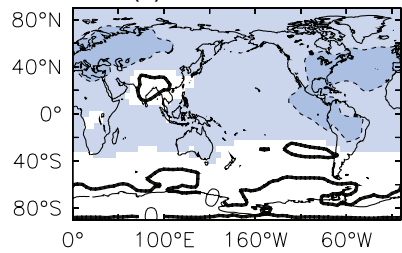

(e) RCP4.5 2030

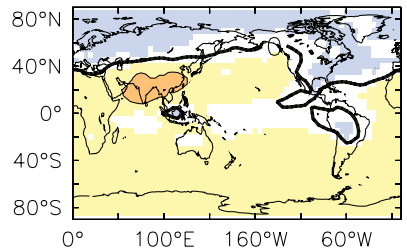

(g) RCP6.0 2030

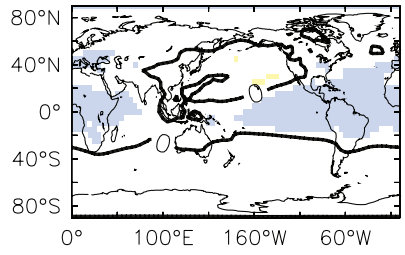

(i) RCP8.5 2030

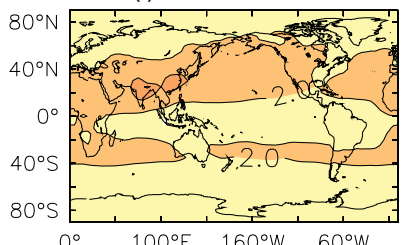

$0^{\circ} \quad 100^{\circ} \mathrm{E} \quad 160^{\circ} \mathrm{W} \quad 60^{\circ} \mathrm{W}$

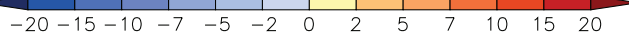

$\Delta \mathrm{O}_{3}$ (trop col) / DU

Fig. 10. As Fig. 9, but for the absolute change in the tropospheric ozone column (DU).

2011). For the regions of significant change, the standard deviation of the differences can exceed $100 \%$ of the ensemble mean difference, though generally only for surface and column values close to emission regions. (By construction, the colour-filled regions of Figs. 9-11 indicate where most models agree on the sign of change, but they do not show where there are large ranges modelled for positive or negative changes.) However, as noted for changes in the total tropospheric burden, there is no apparent correlation with a model's present day ozone level in one region and the change in ozone that is modelled for the same region. 
(a) Hist 1850

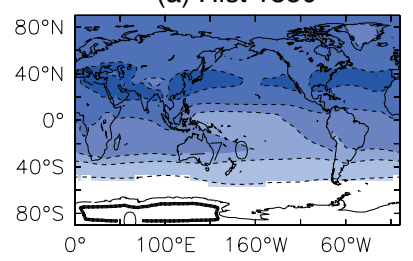

(c) RCP2.6 2030

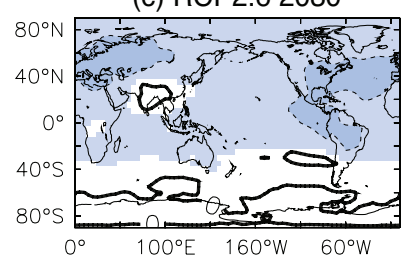

(e) RCP4.5 2030

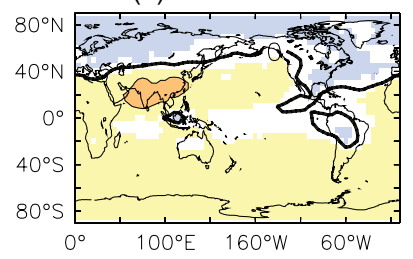

(g) RCP6.0 2030

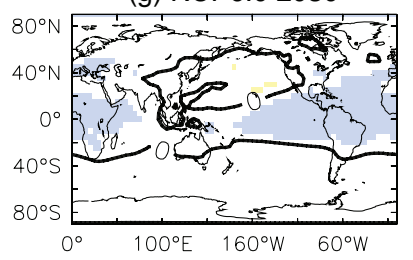

(i) RCP8.5 2030

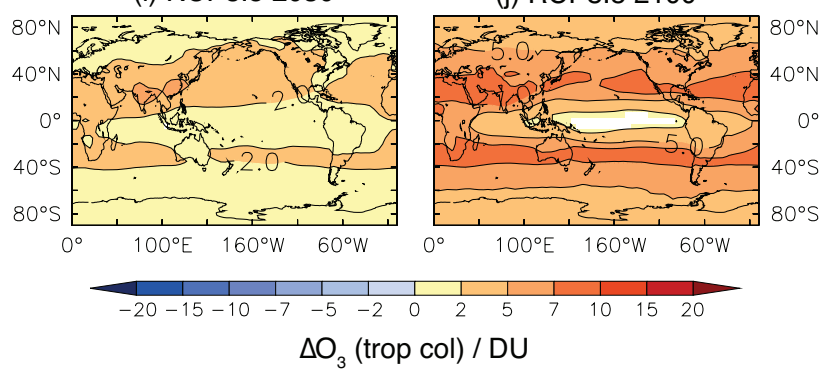

Fig. 11. As Fig. 9, but for the absolute change in surface ozone (ppbv).

Model agreement on the distribution of the differences is very good, with most models being highly spatially correlated with the ensemble mean difference (see Figs. S4S6). Notable exceptions are LMDz-OR-INCA and CICEROOsloCTM2, which have fixed stratospheric ozone levels or influx. This testifies to the potential importance of stratospheric circulation and ozone changes for tropospheric ozone projections, as most of those models that include some representation of stratospheric ozone evolution have changes that are generally well correlated with each other. However, for RCP8.5 2100 MOCAGE and STOC-HadAM3 are not well correlated with the other models, despite having some repre- sentation of stratospheric ozone change. MOCAGE strongly concentrates tropospheric ozone increases at high latitudes rather than the mid latitudes and tropics as per Figs. 9j and $10 \mathrm{j}$. This could relate to systematic differences in the locations of stratosphere-to-troposphere ozone transport, the distribution of stratospheric ozone, or a combination of the two. While STOC-HadAM3 makes use of the time-evolving stratospheric ozone dataset of Cionni et al. (2011), it uses it to help constrain ozone concentrations at the model top, rather than simply to overwrite ozone above the tropopause. This may account for the outlying stratospheric ozone trends seen for this model in the supplementary material. A STOCHadAM3 simulation where only the climate is changed to RCP8.5 2100 conditions concentrates tropospheric ozone column increases over continental regions, perhaps implying a stronger role for $\mathrm{LNO}_{\mathrm{x}}$ increases instead of more stratospheric ozone influx (see supplementary material of Stevenson et al. (2012) and below).

\subsection{Ozone budget changes for a subset of models}

We can gain additional insight into some of the processes controlling global tropospheric ozone changes from the limited ozone budget data. Figure 12 shows the percentage change in the tropospheric ozone budget terms (P, L, P minus $\mathrm{L}, \mathrm{D}, \mathrm{S}_{\mathrm{inf}}$ and $\tau$ ) for all the scenarios and time slices compared to Hist 2000, showing only the five ACCMIP models where there are sufficient data (see Table 2; GEOSCCM had only Hist data available). We concentrate on the relative changes to minimise the impact of different budget definitions and the range of different model scheme complexities (e.g. higher VOC emissions tend to mean higher P and L). Note, not all five models are represented for each variable or time slice.

Figure 12a-b show that the relative changes in the $\mathrm{P}$ and $\mathrm{L}$ terms qualitatively resemble the changes in the tropospheric ozone burden in Fig. 7b. Individual models tend to agree on the magnitude of the relative changes to within 10-20\%, although absolute changes differ more. Compared to Hist 2000 , changes in the net chemical production (NCP, P minus L; Fig. 12c) are overwhelmingly negative for all time slices and models (the RCP8.5 2030 time slice change for STOCHadAM3 is the only exception), likely aided by an increase in the water-mediated loss of ozone (via $\mathrm{O}\left({ }^{1} \mathrm{D}\right)+\mathrm{H}_{2} \mathrm{O}$ ) for the RCPs due to higher specific humidity in the warmer climates (see Fig. 10 of Lamarque et al., 2013). Despite the reductions in NCP, for most models the absolute value of NCP is positive for all time slices, with net chemical destruction only shown for some CESM-CAM-superfast (Hist 1850, RCP2.6. 2100 and RCP6.5 2100) and UM-CAM (Hist 1850, RCP2.6. 2100, RCP4.5 2100 and RCP8.5 2100) time slices. The relative changes in D (Fig. 12d) are qualitatively similar to those for $\mathrm{P}$ and $\mathrm{L}$, although, notably, with smaller relative changes for RCP8.5 2100. Changes in D will depend on the 

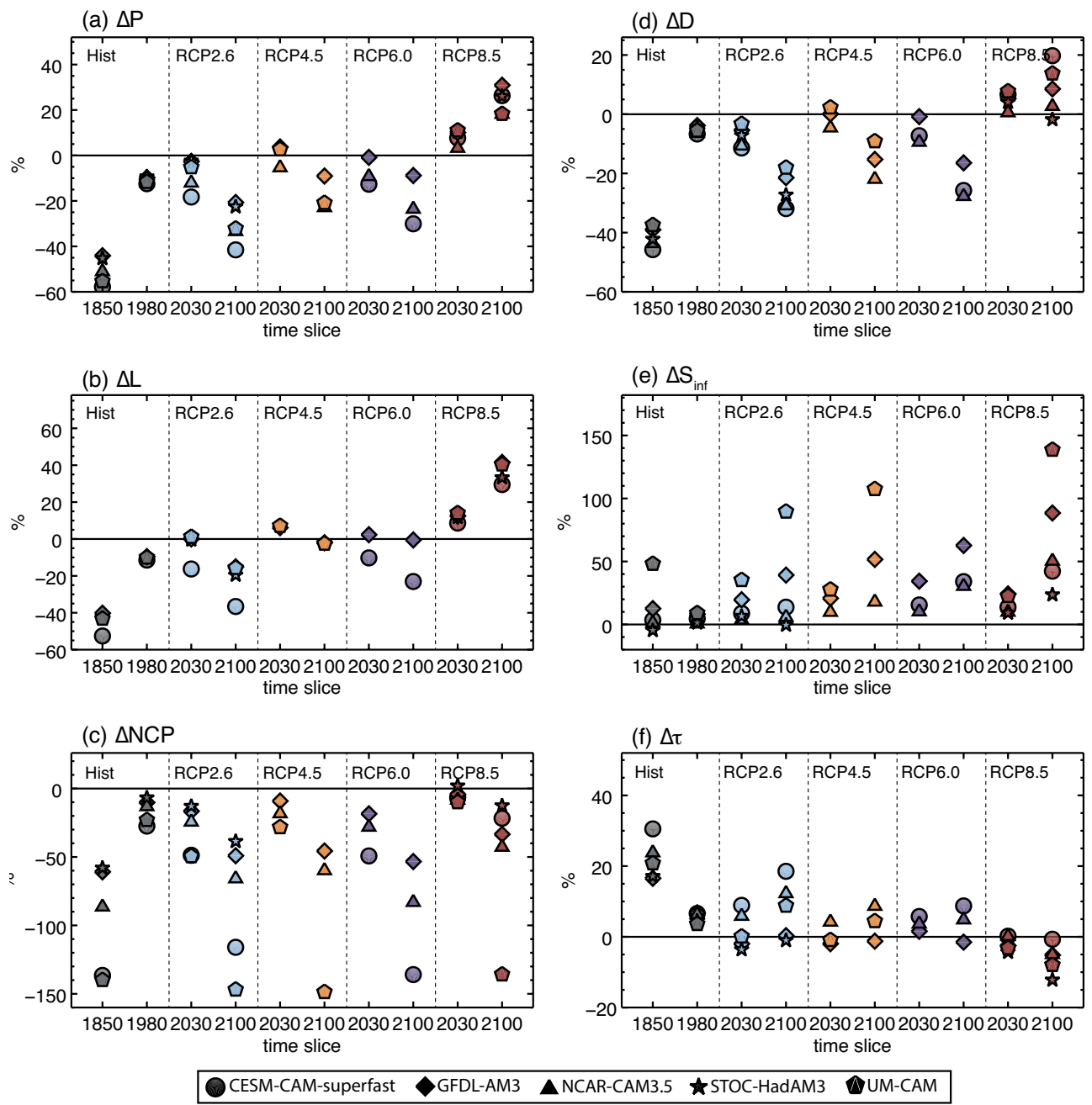

Fig. 12. Relative change in tropospheric ozone budget terms compared to Hist 2000, for all scenarios and time slices, for the subset ACCMIP models with data. Construction is similar to Fig. 7b, except the box/whisker is replaced with a symbol for each model. Relative changes are shown for (a) chemical production (P), (b) chemical loss (L), (c) net chemical production (NCP; P minus L), (d) dry deposition (D), (e) inferred stratospheric input $\left(\mathrm{S}_{\mathrm{inf}}\right)$ and $(\mathbf{f})$ lifetime $(\tau)$.

distribution of near-surface ozone changes (Fig. 11) as well as the characteristics of the deposition schemes.

Figure 12e shows that changes in $\mathrm{S}_{\text {inf }}$ vary more between the models. Moreover, the size of the change is qualitatively related to the magnitude of $S_{\text {inf }}$ in the Hist 2000 slice: UMCAM has the largest Hist $2000 S_{\text {inf }}$ and the largest changes in $\mathrm{S}_{\mathrm{inf}}$, whereas STOC-HadAM3 has the smallest Hist $2000 \mathrm{~S}_{\mathrm{inf}}$ and the smallest changes in $S_{\text {inf }}$ (see Sect. 5.2 for further discussion on the different treatment of the stratosphere). Except for some STOC-HadAM3 results (Hist 1850 and RCP2.6 2100 ), all models show an increase in $S_{\text {inf }}$ for all time slices compared to Hist 2000. As most simulations also show a decrease in $\mathrm{P}$, the increases in $S_{\text {inf }}$ point to the increased importance for that tropospheric ozone source term under historical and projected conditions. For UM-CAM, $S_{\text {inf }}$ is half the size of P for Hist 1850, 40\% of P for RCP2.6 2100 and $30 \%$ of P for RCP8.5 2100; $\mathrm{S}_{\mathrm{inf}}$ varies between $7-22 \%$ of
$\mathrm{P}$ for the other models. The general increase in $\mathrm{S}_{\text {inf }}$ for the RCPs is consistent with the qualitative analysis in Sect. 5.2 and Kawase et al. (2011).

Figure $12 \mathrm{f}$ shows that the relative changes in $\tau$ are smaller than for the other terms, being most notable for the scenarios with larger emission reductions compared to Hist 2000. These are namely Hist 1850 (3.6 to 7.8 day longer lifetime) and, to a lesser extent, RCP2.6 2100 (0.2 day shorter lifetime to 4.7 day longer lifetime). While Kawase et al. (2011) are mostly in agreement with this limited ACCMIP ensemble for RCP2.6. and RCP8.5 lifetime changes, they report lifetime decreases for RCP4.5 and RCP6.0, where the ACCMIP model spread suggests an ambiguous result.

Overall, as in Sect. 4.1, we caution that the ACCMIP results cannot be used for a consistent comparison, due to the different methods of determining $\mathrm{P}$ and $\mathrm{L}$ (and therefore 

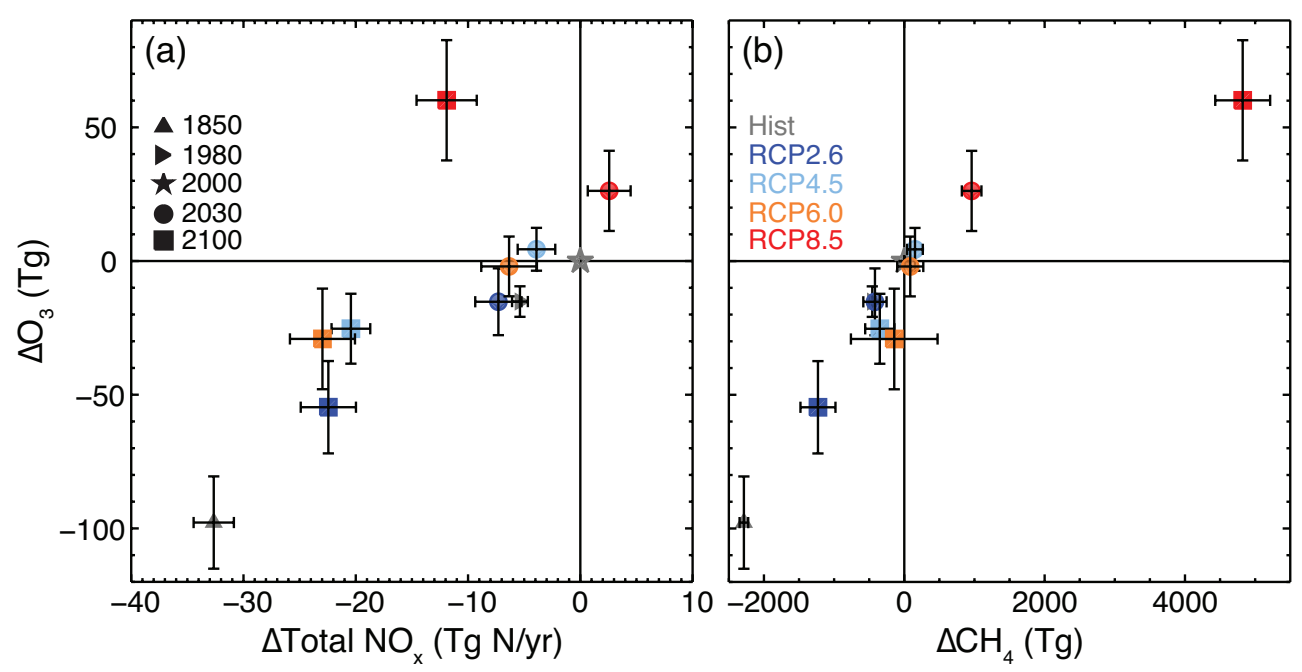

Fig. 13. ACCMIP ensemble mean change in the tropospheric ozone burden compared to the Hist 2000 simulation as a function of (a) changes in total $\mathrm{NO}_{\mathrm{x}}$ emissions and (b) changes in the tropospheric methane burden. Error bars indicate \pm 1 std. dev. of the changes in ozone, $\mathrm{NO}_{\mathrm{x}}$ emissions and methane burdens, calculated from the spread of the models. Different colours represent the different scenarios, whereas different symbols represent the different time slices.

$\mathrm{NCP}$ ), but are nevertheless instructive for future comparisons.

\section{4 $\mathrm{NO}_{\mathrm{x}}$, methane and the implied role of climate change as drivers of the total ozone changes}

The relationship of modelled tropospheric ozone burdens with methane and $\mathrm{NO}_{\mathrm{x}}$ is well established (Stevenson et al., 2006; Wild, 2007; Fiore et al., 2008; Wild et al., 2012) and Fig. 13 presents how the ACCMIP ensemble mean ozone burden changes for each simulation, together with (a) changes in the mean $\mathrm{NO}_{\mathrm{x}}$ emission and (b) changes in the mean tropospheric methane burden.

Figure 13a shows that the evolution of tropospheric ozone from the pre-industrial period to present day tracks the change in $\mathrm{NO}_{\mathrm{x}}$ emissions in a near linear fashion, similar to the relationship presented by Stevenson et al. (2006). The decrease in $\mathrm{NO}_{\mathrm{x}}$ emissions for RCP2.6, 4.5 and 6.0 sees the ozone burden decrease again, although at a slightly reduced rate than for the Hist simulations partially due to the redistribution of precursor emissions equatorward, where the ozone production efficiency is greater (Gupta et al., 1998; Wild and Palmer, 2008). This is particularly the case for RCP4.5 2030, which - as noted in Sect. 5.2 - has an increase in tropical $\mathrm{NO}_{\mathrm{x}}$ emissions compared to Hist 2000, despite an overall decrease.

RCP8.5 is the clear outlier for the simple $\mathrm{NO}_{\mathrm{x}}$-ozone relationship, with a $60 \mathrm{Tg}$ increase in the tropospheric ozone burden coupled with a $12 \mathrm{Tg} \mathrm{N} \mathrm{yr}^{-1}$ reduction in $\mathrm{NO}_{\mathrm{x}}$ emissions. Based on the results of the other simulations, and only considering $\mathrm{NO}_{\mathrm{x}}$ changes, we might expect a $40-50 \mathrm{Tg}$ decrease in the tropospheric ozone burden. However, as already stated, a defining feature of RCP8.5 is the large increase in methane concentrations through the 21 st century, and the relationship between ozone changes and methane changes for the simulations is shown in Fig. 13b. Taking in data across all the simulations shows that the relationship is not linear, and it clearly partially depends on the levels of other ozone precursors, as well as their distribution (e.g. see Wild, 2007). For instance, the change between Hist 2000 and RCP8.5 2030 qualitatively sits on the same line as the ozone-methane relationship for the Hist simulations, likely due to the methane increase in RCP8.5 2030 being accompanied by an increase in $\mathrm{NO}_{\mathrm{x}}$ emissions. Between 2030 and 2100, the reduction $\mathrm{NO}_{\mathrm{x}}$ (and other) emissions for RCP8.5 contributes to the fact that a given methane increase does not produce as much of an ozone increase.

The impacts of climate change further complicate this correlation. Using the parameterised relationship between ozone abundance and the levels of its precursor emissions (but excluding climate) developed by Wild et al. (2012), we would expect an ozone burden increase of approximately $30 \mathrm{Tg}$ between Hist 2000 and RCP8.5 in 2100. However, at $60 \mathrm{Tg}$ the ACCMIP ensemble mean increase in ozone is double that expected, and consistent with equal roles for methane increases and the net impacts of climate change, i.e. through promoting increased influx of stratospheric ozone, changing $\mathrm{LNO}_{\mathrm{x}}$, and impacting reaction rates, through temperature and humidity changes. This is broadly similar to result from the RCP8.5 sensitivity simulations of Kawase et al. (2011), which showed a 5.5 DU increase in the global mean tropospheric column when all drivers changed, and a 2.0 DU increase when only (non-methane) greenhouse gases changed - i.e. assuming linearity, climate change accounted for $36 \%$ of the total tropospheric ozone change. We have 
some evidence for the importance of the stratosphere in the ACCMIP ensemble from the large increases in $S_{\text {inf }}$ for RCP8.5 2100 (Fig. 12d), although it would be more instructive to have this data for all models.

\section{Discussion}

Considering the full ACCMIP ensemble, the results for ozone change are most unambiguous for Hist 1850, RCP2.6 2100 and RCP8.5 2100, both in terms of magnitude and distribution. These represent the extremes of the spectrum of historical and RCP scenarios, with the former two having the lowest concentrations of all ozone precursors, and RCP8.5 having relatively low $\mathrm{NO}_{\mathrm{x}}, \mathrm{CO}$ and NMVOC emissions, but very high methane coupled with a strong warming (see Lamarque et al., 2013). With the generally low concentrations of the more "complex" VOC precursors, "basic" tropospheric chemistry (i.e. involving methane, $\mathrm{CO}, \mathrm{NO}_{\mathrm{x}}, \mathrm{HO}_{\mathrm{x}}$ and ozone) becomes more important. The reactions describing this chemistry are generally very similarly represented in most models (e.g. Emmerson and Evans, 2009), and, with the reduced importance of the chemistry of more complex VOCs, this could potentially be driving a lot of the similarity between the models. The relative changes in the $\mathrm{P}$ and $\mathrm{L}$ terms for the subset of ACCMIP models with budget data are reasonably well clustered (Figs. 12a and 12b), but uncertainty in the interpretation would be reduced if the whole ensemble were better represented. Further useful information could come from a systematic investigation of the response of ozone to idealised precursor changes in the different models, such as through the sensitivity studies of Wild (2007).

While there is good agreement between the models for the ozone changes between Hist 1850 and Hist 2000, we note that none of the ACCMIP models can reproduce the low surface ozone concentrations suggested by late-19th century measurements using the Schönbein method (Pavelin et al., 1999; Hauglustaine and Brasseur, 2001). Compared to the data presented by Hauglustaine and Brasseur (2001), biases for the ensemble mean are 40-350\% (not shown). This result has not changed greatly over the last two decades (e.g. Pavelin et al., 1999). Indeed, one of the only model studies to simulate ozone in-line with these Schönbein data invoked large perturbations in the emissions of $\mathrm{VOC}$ and $\mathrm{NO}_{\mathrm{x}}$, compared to those imposed in this study (Mickley et al., 2001).

As well as uncertainty in ozone precursor emissions, there is scope for uncertainty in the representation of the oxidation chemistry during the cleaner pre-industrial period, where, in particular, levels of $\mathrm{NO}_{\mathrm{x}}$ are expected to have been much lower than today. Since isoprene emissions may not have changed dramatically since the pre-industrial period (e.g. Arneth et al., 2010), modifications to the low-NO ${ }_{x}$ chemistry of isoprene may be important. Novel isoprene chemistry has recently been included in simulations of pre-industrial ozone by Archibald et al. (2011). However, the changes they im- posed to rectify problems with simulating surface $\mathrm{OH}$ in the tropics led to an increase in surface ozone everywhere. Biogenic hydrocarbon emissions play a dual role in ozone production acting as ozone precursors on the one hand but also many are able to react directly with ozone at a fast rate, or decrease ozone production by sequestering $\mathrm{NO}_{\mathrm{x}}$ (Fiore et al., 2005; Horowitz et al., 2007; Young et al., 2009). Recently, tropospheric halogen chemistry has been postulated as being an important process missing in many models that have attempted to simulate pre-industrial ozone (Parrella et al., 2012; Saiz-Lopez et al., 2012), but such processes were not included in the ACCMIP models. Clearly, more understanding of all these processes is important for simulating past and future tropospheric ozone.

\section{Summary and conclusions}

This study has analysed tropospheric ozone changes from 1850 to 2100 from the range of chemistry models that contributed to the Atmospheric Chemistry and Climate Model Intercomparison Project (ACCMIP), running the latest set of ozone precursor emissions scenarios, and with 14 out of 15 models also including representations of the changing climate. The ensemble mean ozone distribution compares favourably with present day satellite and ozonesonde observations. The seasonal cycle is well captured, except in some locations in the tropical upper troposphere, and there are suggestions of a high bias in the Northern Hemisphere $(\mathrm{NH})$ and a low bias in the Southern Hemisphere (SH), although most model results fall within the range of observed interannual variability.

In agreement with other studies (e.g. Lamarque et al., 2005), the modelled tropospheric ozone burden in 1850 is $\sim 30 \%$ lower than the present day, with the largest contribution to the change coming from the $\mathrm{NH}$ extratropics. Intermodel agreement on the magnitude of this change is reasonably high $(98 \pm 17 \mathrm{Tg})$, although modelled surface ozone concentrations are higher than the available pre-industrial measurements (as per Hauglustaine and Brasseur, 2001) suggesting that there are still unresolved issues with correctly modelling pre-industrial ozone levels (Mickley et al., 2001). Modelled ozone also increases somewhat between 1980 and 2000, particularly over industrialised regions in the $\mathrm{NH}$, in agreement with the general picture described by Parrish et al. (2012).

Future changes in tropospheric ozone were considered for 2030 and 2100 time slices, using projections of climate and ozone precursor emissions from four Representative Concentration Pathways (RCPs). Compared to 2000, the relative changes for the tropospheric ozone burden in 2030 (2100) for the different RCPs are: $-4 \%(-16 \%)$ for RCP2.6, $2 \%$ $(-7 \%)$ for RCP4.5, $-1 \%(-9 \%)$ for RCP6.0, and $7 \%$ $(18 \%)$ for RCP8.5. The decreases apparent for most RCPs are due to reductions in precursor emissions, but the increase 
in ozone for RCP8.5 is in spite of reductions in nitrogen oxide emissions. From the limited ACCMIP ozone budget data and as implied by comparison to other studies (Kawase et al., 2011; Wild et al., 2012), the RCP8.5 ozone increase can be attributed to the very large increase ( $\sim$ doubling) in methane and increased stratospheric influx of ozone (40$150 \%$ increase, as determined from the five models with ozone budget data). Inter-model agreement on the magnitude of the total change compared to 2000 is best where the changes are large, such as for RCP 2.6 in $2100(-55 \pm 16 \mathrm{Tg})$ and RCP8.5 in $2100(60 \pm 22 \mathrm{Tg})$. While models with higher present day ozone burdens have higher ozone burdens for the other time slices, there is no relationship between burden and burden change, or between burden changes for different periods/scenarios. This key result suggests that any model weighting schemes based on the present day model bias (e.g. versus OMI-MLS) will not necessarily reduce the model spread for future projections.

For the changes with all RCPs, generally the models are highly spatially correlated with one another, agreeing on where the changes are occurring, if not their magnitude. Notable exceptions are for the models that do not include representation of the changing influence of the stratosphere on the troposphere, highlighting the importance of ozone recovery (Eyring et al., 2010) and climate change-induced circulation strengthening (Butchart et al., 2006; Butchart et al., 2010; SPARC-CCMVal, 2010) in this region of the atmosphere.

Overall, we have shown that the multi-model mean of ACCMIP models generally simulates present day tropospheric ozone well, and agrees on the sign of past and future tropospheric ozone changes and how those changes are distributed. Fully establishing the consistency of the chemical and physical processes driving the changes in the different models is limited in this study due to lack of comparable ozone budget statistics. For example, we cannot explain the lack of a correlation between the present day tropospheric ozone burden and pre-industrial to present day burden change, something which may be attributed to different model sensitivities to precursor emission changes, combined with a range of ozone fluxes from the stratosphere. Future studies will require careful thought as to how to make the necessary diagnostics comparable across models and we encourage discussion and further study within the chemistryclimate community of how best to manage this. In addition, the chemistry community would benefit from a thorough investigation into the importance of the different processes that control tropospheric ozone, as has been examined for cloud condensation nuclei in aerosol models (Lee et al., 2012). Finally, like Kawase et al. (2011), this study highlights the strong influence of stratospheric processes in controlling tropospheric ozone, which may encourage more tropospheric chemistry-climate modelling groups to move towards full atmosphere simulations.
Acknowledgements. ACCMIP is organised under the auspices of the International Global Atmospheric Chemistry (IGAC) and Stratospheric Processes And their Role in Climate (SPARC) projects, which fall under the International Geosphere-Biosphere Project (IGBP) and World Climate Research Program (WCRP) respectively. The authors are grateful to the British Atmospheric Data Centre (BADC), which is part of the NERC National Centre for Atmospheric Science (NCAS), for collecting and archiving the ACCMIP data. For CESM-CAM-superfast, DB and PC were funded by the US Dept. of Energy (BER) and simulations were performed under the auspices of LLNL under Contract DE-AC52-07NA27344, and using the supercomputing resources of NERSC under contract No. DE-AC02-05CH11231. The CICERO-OsloCTM2 simulations were completed within the projects SLAC (Short Lived Atmospheric Components) and EarthClim funded by the Norwegian Research Council. DP would like to thank the Canadian Foundation for Climate and Atmospheric Sciences for their long-running support of CMAM development. For EMAC, the work of VE and MR was funded by the DLR Earth System Model Validation (ESMVal) project and used the supercomputing resources of the German Climate Computing Center (DKRZ) and the Leibniz Supercomputing Centre (LRZ), and the work of IC was funded by the ENEA National Integrated Model to support the international negotiation on atmospheric pollution (Minni) project. The GEOSCCM work was supported by the NASA Modeling, Analysis and Prediction program, with computing resources provided by NASA's High-End Computing Program through the NASA Advanced Supercomputing Division. VN and LWH acknowledge efforts of GFDL's Global Atmospheric Model Development Team in the development of the GFDL-AM3 and Modeling Services Group for assistance with data processing. For the GISS models, support is acknowledged from the NASA MAP and ACMAP programs. For HadGEM2, WJC and STR were supported by the Joint DECC and Defra Integrated Climate Programme (GA01101). The LMDz-OR-INCA simulations were done using computing resources provided by the CCRT/GENCI computer centre of the CEA. The MOCAGE simulations were supported by Météo-France and CNRS and supercomputing time was provided by the Météo-France/DSI supercomputing centre. The MIROC-CHEM calculations were performed on the NIES supercomputer system (NEC SX-8R), and supported by the Environment Research and Technology Development Fund (S-7) of the Ministry of the Environment, Japan. The CESM project, including NCAR-CAM3.5, is supported by the National Science Foundation and the Office of Science (BER) of the US Department of Energy. The National Center for Atmospheric Research is operated by the University Corporation for Atmospheric Research under sponsorship of the National Science Foundation. The STOC-HadAM3 work was supported by cross UK research council grant NE/I008063/1 and used facilities provided by the UK's national high-performance computing service, HECToR, through Computational Modelling Services (CMS), part of the NERC National Centre for Atmospheric Science (NCAS). For UM-CAM, GZ acknowledges NIWA HPCF facility and funding from New Zealand Ministry of Science and Innovation.

Edited by: H. Tost 


\section{References}

Allen, D. J. and Pickering, K. E.: Evaluation of lightning flash rate parameterizations for use in a global chemical transport model, J. Geophys. Res., 107, 4711, doi:10.1029/2002JD002066, 2002.

Archibald, A. T., Jenkin, M. E., and Shallcross, D. E.: An isoprene mechanism intercomparison, Atmos. Environ., 44, 5356-5364, doi:10.1016/j.atmosenv.2009.09.016, 2010.

Archibald, A. T., Levine, J. G., Abraham, N. L., Cooke, M. C., Edwards, P. M., Heard, D. E., Jenkin, M. E., Karunaharan, A., Pike, R. C., Monks, P. S., Shallcross, D. E., Telford, P. J., Whalley, L. K., and Pyle, J. A.: Impacts of HOx regeneration and recycling in the oxidation of isoprene: Consequences for the composition of past, present and future atmospheres, Geophys. Res. Lett., 38, L05804, doi:10.1029/2010GL046520, 2011.

Arneth, A., Miller, P. A., Scholze, M., Hickler, T., Schurgers, G., Smith, B., and Prentice, I. C.: CO2 inhibition of global terrestrial isoprene emissions: Potential implications for atmospheric chemistry, Geophys. Res. Lett., 34, L18813, doi:10.1029/2007GL030615, 2007a.

Arneth, A., Niinemets, Ü., Pressley, S., Bäck, J., Hari, P., Karl, T., Noe, S., Prentice, I. C., Serça, D., Hickler, T., Wolf, A., and Smith, B.: Process-based estimates of terrestrial ecosystem isoprene emissions: incorporating the effects of a direct $\mathrm{CO}_{2}$-isoprene interaction, Atmos. Chem. Phys., 7, 31-53, doi:10.5194/acp-7-31-2007, 2007b.

Arneth, A., Schurgers, G., Hickler, T., and Miller, P. A.: Effects of species composition, land surface cover, $\mathrm{CO} 2$ concentration and climate on isoprene emissions from European forests, Plant Biol., 10, 150-162, doi:10.1055/s-2007-965247, 2008.

Arneth, A., Harrison, S. P., Zaehle, S., Tsigaridis, K., Menon, S., Bartlein, P. J., Feichter, J., Korhola, A., Kulmala, M., O’donnell, D., Schurgers, G., Sorvari, S., and Vesala, T.: Terrestrial biogeochemical feedbacks in the climate system, Nature Geosci., 3, 525-532, doi:10.1038/ngeo905, 2010.

Arneth, A., Schurgers, G., Lathière, J., Duhl, T., Beerling, D. J., Hewitt, C. N., Martin, M., and Guenther, A.: Global terrestrial isoprene emission models: sensitivity to variability in climate and vegetation, Atmos. Chem. Phys., 11, 8037-8052, doi:10.5194/acp-11-8037-2011, 2011.

Ashworth, K., Folberth, G., Hewitt, C. N., and Wild, O.: Impacts of near-future cultivation of biofuel feedstocks on atmospheric composition and local air quality, Atmos. Chem. Phys., 12, 919939, doi:10.5194/acp-12-919-2012, 2012.

Beer, R.: TES on the aura mission: scientific objectives, measurements, and analysis overview, IEEE Tranactions on Geoscience and Remote Sensing, 44, 1102-1105, doi:10.1109/TGRS.2005.863716, 2006

Bowman, K., Shindell, D., Worden, H., Lamarque, J. F., Young, P. J., Stevenson, D., Qu, Z., de la Torre, M., Bergmann, D., Cameron-Smith, P., Collins, W. J., Doherty, R., Dalsoren, S., Faluvegi, G., Folberth, G., Horowitz, L. W., Josse, B., Lee, Y. H., MacKenzie, I., Myhre, G., Nagashima, T., Naik, V., Plummer, D., Rumbold, S., Skeie, R., Strode, S., Sudo, K., Szopa, S., Voulgarakis, A., Zeng, G., Kulawik, S., and Worden, J.: Observational constraints on ozone radiative forcing from the Atmospheric Chemistry Climate Model Intercomparison Project (ACCMIP), Atmos. Chem. Phys. Discuss., 12, 23603-23644, doi:10.5194/acpd-12-23603-2012, 2012.
Bowman, K. W., Rodgers, C. D., Kulawik, S. S., Worden, J., Sarkissian, E., Osterman, G., Steck, T., Lou, M., Eldering, A., Shephard, M., Worden, H., Lampel, M., Clough, S., Brown, P., Rinsland, C., Gunson, M., and Beer, R.: Tropospheric emission spectrometer: retrieval method and error analysis, IEEE Transactions on Geoscience and Remote Sensing, 44, 1297-1307, doi:10.1109/TGRS.2006.871234, 2006.

Brasseur, G. P., Schultz, M. G., Granier, C., Saunois, M., Diehl, T., Botzet, M., Roeckner, E., and Walters, S.: Impact of climate change on the future chemical composition of the global troposphere, J. Clim., 19, 3932-3951, 2006.

Butchart, N., Scaife, A. A., Bourqui, M. S., de Grandpré, J., Hare, S. H. E., Kettleborough, J. A., Langematz, U., Manzini, E., Sassi, F., Shibata, K., Shindell, D. T., and Sigmond, M.: Simulations of anthropogenic change in the strength of the Brewer-Dobson circulation, Clim. Dynam., 27, 727-741, doi:10.1007/s00382-0060162-4, 2006.

Butchart, N., Cionni, I., Eyring, V., Shepherd, T. G., Waugh, D. W., Akiyoshi, H., Austin, J., Brühl, C., Chipperfield, M. P., Cordero, E., Dameris, M., Deckert, R., Dhomse, S., Frith, S. M., Garcia, R. R., Gettelman, A., Giorgetta, M. A., Kinnison, D. E., Li, F., Mancini, E., Mclandress, C., Pawson, S., Pitari, G., Plummer, D. A., Rozanov, E., Sassi, F., Scinocca, J. F., Shibata, K., Steil, B., and Tian, W.: Chemistry-Climate Model Simulations of TwentyFirst Century Stratospheric Climate and Circulation Changes, J. Clim., 23, 5349-5374, doi:10.1175/2010JCLI3404.1, 2010.

Christoudias, T., Pozzer, A., and Lelieveld, J.: Influence of the North Atlantic Oscillation on air pollution transport, Atmos. Chem. Phys., 12, 869-877, doi:10.5194/acp-12-869-2012, 2012.

Cionni, I., Eyring, V., Lamarque, J. F., Randel, W. J., Stevenson, D. S., Wu, F., Bodeker, G. E., Shepherd, T. G., Shindell, D. T., and Waugh, D. W.: Ozone database in support of CMIP5 simulations: results and corresponding radiative forcing, Atmos. Chem. Phys., 11, 11267-11292, doi:10.5194/acp-11-11267-2011, 2011.

Collins, W. J., Derwent, R. G., Garnier, B., Johnson, C. E., Sanderson, M. G., and Stevenson, D. S.: Effect of stratospheretroposphere exchange on the future tropospheric ozone trend, J Geophys. Res., 108, 8528, doi:10.1029/2002JD002617, 2003.

Dentener, F. J., Stevenson, D. S., Cofala, J., Mechler, R., Amann, M., Bergamaschi, P., Raes, F., and Derwent, R. G.: The impact of air pollutant and methane emission controls on tropospheric ozone and radiative forcing: CTM calculations for the period 1990-2030, Atmos. Chem. Phys., 5, 1731-1755, doi:10.5194/acp-5-1731-2005, 2005.

Dentener, F. J., Stevenson, D. S., Ellingsen, K., van Noije, T. P. C., Schultz, M. G., Amann, M., Atherton, C. S., Bell, N., Bergmann, D. J., Bey, I., Bouwman, A. J., Butler, T., Cofala, J., Collins, W. J., Drevet, J., Doherty, R. M., Eickhout, B., Eskes, H. J., Fiore, A. M., Gauss, M., Hauglustaine, D. A., Horowitz, L. W., Isaksen, I. S. A., Josse, B., Lawrence, M. G., Krol, M., Lamarque, J.F., Montanaro, V., Müller, J.-F., Peuch, V. H., Pitari, G., Pyle, J. A., Rast, S., Rodriguez, J. M., Sanderson, M. G., Savage, N. H., Shindell, D. T., Strahan, S. E., Szopa, S., Sudo, K., van Dingenen, R., Wild, O., and Zeng, G.: The global atmospheric environment for the next generation, Environ. Sci. Technol., 40, 3586-3594, doi:10.1021/es0523845, 2006.

Doherty, R. M., Stevenson, D. S., Collins, W. J., and Sanderson, M. G.: Influence of convective transport on tropospheric ozone and its precursors in a chemistry-climate model, Atmos. Chem. 
Phys., 5, 3205-3218, doi:10.5194/acp-5-3205-2005, 2005.

Eckhardt, S., Stohl, A., Beirle, S., Spichtinger, N., James, P., Forster, C., Junker, C., Wagner, T., Platt, U., and Jennings, S. G.: The North Atlantic Oscillation controls air pollution transport to the Arctic, Atmos. Chem. Phys., 3, 1769-1778, doi:10.5194/acp-31769-2003, 2003.

Emmerson, K. M. and Evans, M. J.: Comparison of tropospheric gas-phase chemistry schemes for use within global models, Atmos. Chem. Phys., 9, 1831-1845, doi:10.5194/acp-9-1831-2009, 2009.

Eyring, V., Cionni, I., Bodeker, G. E., Charlton-Perez, A. J., Kinnison, D. E., Scinocca, J. F., Waugh, D. W., Akiyoshi, H., Bekki, S., Chipperfield, M. P., Dameris, M., Dhomse, S., Frith, S. M., Garny, H., Gettelman, A., Kubin, A., Langematz, U., Mancini, E., Marchand, M., Nakamura, T., Oman, L. D., Pawson, S., Pitari, G., Plummer, D. A., Rozanov, E., Shepherd, T. G., Shibata, K., Tian, W., Braesicke, P., Hardiman, S. C., Lamarque, J. F., Morgenstern, O., Pyle, J. A., Smale, D., and Yamashita, Y.: Multimodel assessment of stratospheric ozone return dates and ozone recovery in CCMVal-2 models, Atmos. Chem. Phys., 10, 94519472, doi:10.5194/acp-10-9451-2010, 2010.

Eyring, V., Cionni, I., Arblaster, J., Sedlacek, J., Perlwitz, J., Young, P. J., Bekki, S., Bergmann, D., Cameron-Smith, P., Collins, W., Faluvegi, G., Gottschaldt, K.-D., Horowitz, L., Kinnison, D., Lamarque, J.-F., Marsh, D. R., Saint-Martin, D., Shindell, D., Sudo, K., Szopa, S. and Watanabe, S.: Long-term changes in tropospheric and stratospheric ozone and associated climate impacts in CMIP5 simulations, submitted to J. Geophys. Res., 2012.

Fiore, A. M., Horowitz, L. W., Purves, D. W., Levy II, H., Evans, M. J., Wang, Y., Li, Q., and Yantosca, R. M.: Evaluating the contribution of changes in isoprene emissions to surface ozone trends over the eastern United States, J. Geophys. Res., 110, D12303, doi:10.1029/2004JD005485, 2005.

Fiore, A. M., Horowitz, L. W., Dlugokencky, E. J., and West, J. J.: Impact of meteorology and emissions on methane trends, 1990-2004, Geophys. Res. Lett., 33, L12809, doi:10.1029/2006GL026199, 2006.

Fiore, A. M., West, J. J., Horowitz, L. W., Naik, V., and Schwartzkopf, M. D.: Characterizing the tropospheric ozone response to methane emission controls and the benefits to climate and air quality, J. Geophys. Res., 113, D08307, doi:10.1029/2007JD009162, 2008.

Fiore, A. M., Dentener, F. J., Wild, O., Cuvelier, C., Schultz, M. G., Hess, P., Textor, C., Schulz, M., Doherty, R. M., Horowitz, L. W., MacKenzie, I. A., Sanderson, M. G., Shindell, D. T., Stevenson, D. S., Szopa, S., van Dingenen, R., Zeng, G., Atherton, C. S., Bergmann, D. J., Bey, I., Carmichael, G. R., Collins, W. J., Duncan, B. N., Faluvegi, G., Folberth, G. A., Gauss, M., Gong, S., Hauglustaine, D., Holloway, T., Isaksen, I. S. A., Jacob, D. J., Jonson, J. E., Kaminski, J. W., Keating, T. J., Lupu, A., Marmer, E., Montanaro, V., Park, R. J., Pitari, G., Pringle, K. J., Pyle, J. A., Schroeder, S., Vivanco, M. G., Wind, P., Wojcik, G., Wu, S., and Zuber, A.: Multimodel estimates of intercontinental sourcereceptor relationships for ozone pollution, J. Geophys. Res., 114, D04301, doi:doi:10.1029/2008JD010816, 2009.

Fishman, J., Watson, C. E., Larsen, J. C., and Logan, J. A.: Distribution of Tropospheric Ozone Determined From Satellite Data, J. Geophys. Res., 95, 3599-3617, doi:10.1029/JD095iD04p03599,
1990.

Fuglestvedt, J. S., Jonson, J. E., and Isaksen, I. S. A.: Effects of reductions in stratospheric ozone on tropospheric chemistry through changes in photolysis rates, Tellus B, 46, 172-192, doi:10.1034/j.1600-0889.1992.t01-3-00001.x-i1, 1994.

Ganzeveld, L., Bouwman, L., Stehfest, E., Vuuren, D. P. v., Eickhout, B., and Lelieveld, J.: Impact of future land use and land cover changes on atmospheric chemistry-climate interactions, J. Geophys. Res., 115, D23301, doi:10.1029/2010JD014041, 2010.

Guenther, A. B., Hewitt, C. N., Erickson, D., Fall, R., Geron, C., Graedel, T. E., Harley, P., Klinger, L., Lerdau, M. T., McKay, W. A., Pierce, T. E., Scoles, B., Steinbrecher, R., Tallaamraju, R., Taylor, J., and Zimmerman, P. R.: A global model of natural volatile organic compound emissions, J. Geophys. Res., 100, 8873-8892, 1995.

Guenther, A. B., Karl, T., Harley, P., Wiedinmyer, C., Palmer, P. I., and Geron, C.: Estimates of global terrestrial isoprene emissions using MEGAN (Model of Emissions of Gases and Aerosols from Nature), Atmos. Chem. Phys., 6, 3181-3210, doi:10.5194/acp-63181-2006, 2006.

Gupta, M. L., Cicerone, R. J., and Elliott, S.: Perturbation to global tropospheric oxidizing capacity due to latitudinal redistribution of surface sources of $\mathrm{NO}_{\mathrm{x}}, \mathrm{CH}_{4}$ and $\mathrm{CO}$, Geophys. Res. Lett., 25, 3931-3934, doi:10.1029/1998GL900099, 1998.

Hauglustaine, D. A. and Brasseur, G. P.: Evolution of tropospheric ozone under anthropogenic activities and associated radiative forcing of climate, J. Geophys. Res., 106, 32337-32360, doi:10.1029/2001JD900175, 2001.

Hauglustaine, D. A., Lathièire, J. A., Szopa, S., and Folberth, G. A.: Future tropospheric ozone simulated with a climatechemistry-biosphere model, Geophys. Res. Lett., 32, L24807, doi:10.1029/2005GL024031, 2005.

Hegglin, M. I. and Shepherd, T. G.: Large climate-induced changes in ultraviolet index and stratosphere-to-troposphere ozone flux, Nature Geosci., 2, 687, doi:10.1038/ngeo604, 2009.

Horowitz, L. W., Fiore, A. M., Mills, G. P., Cohen, R. C., Perring, A. E., Wooldridge, P. J., Hess, P. G., Emmons, L. K., and Lamarque, J.-F.: Observational constraints on the chemistry of isoprene nitrates over the eastern United States, J. Geophys. Res., 112, D12S08, doi:10.1029/2006JD007747, 2007.

Jacob, D. J., Heikes, E. G., Fan, S. M., Logan, J. A., Mauzerall, D. L., Bradshaw, J. D., Singh, H. B., Gregory, G. L., Talbot, R. W., Blake, D. R., and Sachse, G. W.: Origin of ozone and NOx in the tropical troposphere: A photochemical analysis of aircraft observations over the South Atlantic basin, J. Geophys. Res., 101, 24235-24250, doi:10.1029/96JD00336, 1996.

Jacobson, M. Z. and Streets, D. G.: Influence of future anthropogenic emissions on climate, natural emissions, and air quality, J. Geophys. Res., 114, D08118, doi:10.1029/2008JD011476, 2009.

Johnson, C. E., Collins, W. J., Stevenson, D. S., and Derwent, R. G.: Relative roles of climate and emissions changes on future tropospheric oxidant concentrations, J. Geophys. Res., 104, 1863118645, 1999.

Kawase, H., Nagashima, T., Sudo, K., and Nozawa, T.: Future changes in tropospheric ozone under Representative Concentration Pathways (RCPs), Geophys. Res. Lett., 38, L05801, doi:10.1029/2010GL046402, 2011. 
Lamarque, J.-F., Hess, P. G., Emmons, L. K., Buja, L. E., Washington, W. M., and Granier, C.: Tropospheric ozone evolution between 1890 and 1990, J. Geophys. Res., 110, D08304, doi:10.1029/2004JD005537, 2005.

Lamarque, J.-F., Bond, T. C., Eyring, V., Granier, C., Heil, A., Klimont, Z., Lee, D., Liousse, C., Mieville, A., Owen, B., Schultz, M. G., Shindell, D., Smith, S. J., Stehfest, E., van Aardenne, J., Cooper, O. R., Kainuma, M., Mahowald, N., McConnell, J. R., Naik, V., Riahi, K., and van Vuuren, D. P.: Historical (1850-2000) gridded anthropogenic and biomass burning emissions of reactive gases and aerosols: methodology and application, Atmos. Chem. Phys., 10, 7017-7039, doi:10.5194/acp10-7017-2010, 2010.

Lamarque, J.-F., Kyle, G. P., Meinshausen, M., Riahi, K., Smith, S. J., Vuuren, D. P., Conley, A. J., and Vitt, F.: Global and regional evolution of short-lived radiatively-active gases and aerosols in the Representative Concentration Pathways, Clim. Change, 109, 191-212, doi:10.1007/s10584-011-0155-0, 2011.

Lamarque, J.-F., Shindell, D. T., Josse, B., Young, P. J., Cionni, I., Eyring, V., Bergmann, D., Cameron-Smith, P., Collins, W. J., Doherty, R., Dalsoren, S., Faluvegi, G., Folberth, G., Ghan, S. J., Horowitz, L. W., Lee, Y. H., MacKenzie, I. A., Nagashima, T., Naik, V., Plummer, D., Righi, M., Rumbold, S. T., Schulz, M., Skeie, R. B., Stevenson, D. S., Strode, S., Sudo, K., Szopa, S., Voulgarakis, A., and Zeng, G.: The Atmospheric Chemistry and Climate Model Intercomparison Project (ACCMIP): overview and description of models, simulations and climate diagnostics, Geosci. Model Dev., 6, 179-206, doi:10.5194/gmd-6-179-2013, 2013.

Lathièire, J. A., Hauglustaine, D. A., de Noublet-Ducoudré, N., Krinner, G., and Folberth, G. A.: Past and future changes in biogenic volatile organic compound emissions simulated with a global dynamic vegetation model, Geophys. Res. Lett., 32, L20818, doi:10.1029/2005GL024164, 2005.

Lawrence, M. G., Jöckel, P., and von Kuhlmann, R.: What does the global mean $\mathrm{OH}$ concentration tell us?, Atmos. Chem. Phys., 1, 37-49, doi:10.5194/acp-1-37-2001, 2001.

Lawrence, M. G., von Kuhlmann, R., Salzmann, M., and Rasch, P. J.: The balance of effects of deep convective mixing on tropospheric ozone, Geophys. Res. Lett., 30, 1940, doi:10.1029/2003GL017644, 2003.

Lee, L. A., Carslaw, K. S., Pringle, K. J., and Mann, G. W.: Mapping the uncertainty in global CCN using emulation, Atmos. Chem. Phys., 12, 9739-9751, doi:10.5194/acp-12-9739-2012, 2012.

Lelieveld, J. and Dentener, F. J.: What controls tropospheric ozone?, J. Geophys. Res., 105, 3531-3551, doi:10.1029/1999JD901011, 2000.

Li, D. and Shine, K. P.: A 4-dimensional ozone climatology for UGAMP models, University of Reading, Reading, UK, Internal Rep. 35, 1995.

Logan, J. A.: An analysis of ozonesonde data for the troposphere: Recommendations for testing 3-D models and development of a gridded climatology for tropospheric ozone, J. Geophys. Res., 104, 16115-16150, 1999.

Marenco, A., Gouget, H., Nédélec, P., Pagés, J.-P., and Karcher, F.: Evidence of a long-term increase in tropospheric ozone from Pic du Midi data series: Consequences: Positive radiative forcing, J. Geophys. Res., 99, 16617-16632, doi:10.1029/94JD00021, 1994.
Mickley, L. J., Jacob, D. J., and Rind, D.: Uncertainty in preindustrial abundance of tropospheric ozone: Implications for radiative forcing calculations, J. Geophys. Res., 106, 3389-3399, doi:10.1029/2000JD900594, 2001.

Mickley, L. J., Jacob, D. J., Field, B. D., and Rind, D. Climate response to the increase in tropospheric ozone since preindustrial times: A comparison between ozone and equivalent $\mathrm{CO}_{2}$ forcings, J. Geophys. Res., 109, D05106, doi:10.1029/2003JD003653, 2004.

Moxim, W. J., Levy II, H., and Kasibhatla, P. S.: Simulated global tropospheric PAN: Its transport and impact on $\mathrm{NO}_{\mathrm{x}}, \mathrm{J}$. Geophys. Res., 101, 12,621-12638, 1996.

Naik, V., Voulgarakis, A., Fiore, A. M., Horowitz, L. W., Lamarque, J. F., Lin, M., Prather, M. J., Young, P. J., Bergmann, D., Cameron-Smith, P. J., Cionni, I., Collins, W. J., Dalsøren, S. B., Doherty, R., Eyring, V., Faluvegi, G., Folberth, G. A., Josse, B., Lee, Y. H., MacKenzie, I. A., Nagashima, T., van Noije, T. P. C., Plummer, D. A., Righi, M., Rumbold, S. T., Skeie, R., Shindell, D. T., Stevenson, D. S., Strode, S., Sudo, K., Szopa, S., and Zeng, G.: Preindustrial to present day changes in tropospheric hydroxyl radical and methane lifetime from the Atmospheric Chemistry and Climate Model Intercomparison Project (ACCMIP), Atmos. Chem. Phys. Discuss., 12, 30755-30804, doi:10.5194/acpd-1230755-2012, 2012.

Nakicenovic, N., Alcamo, J., Davis, G., de Vries, B., Fenhann, J., Gaffin, S., Gregory, K., Grübler, A., Jung, T. Y., Kram, T., Lebre La Rovere, E., Michaelis, L., Mori, S., Morita, T., Pepper, W., Pitcher, H., Price, L., Riahi, K., Roehrl, A., Rogner, H.-H., Sankovski, A., Schlesinger, M., Shukla, P., Smith, S., Swart, R., van Rooijen, S., Victor, N., and Zhou, D.: Special Report on Emissions Scenarios: A Special Report of Working Group III of the Intergovernmental Panel on Climate Change, Cambridge, UK, 570, 2000.

Nassar, R., Logan, J. A., Worden, H. M., Megretskaia, I. A., Bowman, K. W., Osterman, G. B., Thompson, A. M., Tarasick, D. W., Austin, S., Claude, H., Dubey, M. K., Hocking, W. K., Johnson, B. J., Joseph, E., Merrill, J., Morris, G. A., Newchurch, M., Oltmans, S. J., Posny, F., Schmidlin, F. J., Vömel, H., Whiteman, D. N., and Witte, J. C.: Validation of Tropospheric Emission Spectrometer (TES) nadir ozone profiles using ozonesonde measurements, J. Geophys. Res., 113, D15S17, doi:10.1029/2007JD008819, 2008.

Olsen, M. A., Schoeberl, M. R., and Douglass, A. R.: Stratospheretroposphere exchange of mass and ozone, J. Geophys. Res., 109, D24114, doi:10.1029/2004JD005186, 2004.

Olsen, S. C., McLinden, C. A., and Prather, M. J.: Stratospheric N 2O-NO ysystem: Testing uncertainties in a three-dimensional framework, J. Geophys. Res., 106, 28771, doi:10.1029/2001JD000559, 2001.

Pacifico, F., Harrison, S., Jones, C., and Sitch, S.: Isoprene emissions and climate, Atmos. Environ., 43, 6121-6135, doi:10.1016/j.atmosenv.2009.09.002, 2009.

Parrella, J. P., Jacob, D. J., Liang, Q., Zhang, Y., Mickley, L. J., Miller, B., Evans, M. J., Yang, X., Pyle, J. A., Theys, N., and Van Roozendael, M.: Tropospheric bromine chemistry: implications for present and pre-industrial ozone and mercury, Atmos. Chem. Phys., 12, 6723-6740, doi:10.5194/acp-12-6723-2012, 2012

Parrish, D. D., Law, K. S., Staehelin, J., Derwent, R., Cooper, O. R., Tanimoto, H., Volz-Thomas, A., Gilge, S., Scheel, H. E., Stein- 
bacher, M., and Chan, E.: Long-term changes in lower tropospheric baseline ozone concentrations at northern mid-latitudes, Atmos. Chem. Phys., 12, 11485-11504, doi:10.5194/acp-1211485-2012, 2012.

Pavelin, E. G., Johnson, C. E., Rughooputh, S., and Toumi, R.: Evaluation of pre-industrial surface ozone measurements made using Schönbein's method, Atmos. Environ., 33, 919-929, doi:10.1016/S1352-2310(98)00257-X, 1999.

Prather, M. J., Gauss, M., Berntsen, T. K., Isaksen, I. S. A., Sundet, J. K., Bey, I., Brasseur, G. P., Dentener, F. J., Derwent, R. G., Stevenson, D. S., Grenfell, L., Hauglustaine, D. A., Horowitz, L. W., Jacob, D. J., Mickley, L. J., Lawrence, M. G., von Kuhlmann, R., Müller, J.-F., Pitari, G., Rogers, H. L., Johnson, M., Pyle, J. A., Law, K. S., van Weele, M., and Wild, O.: Fresh air in the 21st century?, Geophys. Res. Lett., 30, 1100, doi:10.1029/2002GL016285, 2003.

Prather, M. J., Zhu, X., Tang, Q., Hsu, J., and Neu, J. L.: An atmospheric chemist in search of the tropopause, J. Geophys. Res., 116, D04306, doi:10.1029/2010JD014939, 2011.

Price, C. and Rind, D. H.: A simple lightning parameterization for calculating global lightning distributions, J. Geophys. Res., 97, 9919-9933, 1992.

Price, C. and Rind, D. H.: Possible implications of global climate change on global lightning distributions and frequencies, J. Geophys. Res., 99, 10823-10831, 1994.

Randel, W. J., Wu, F., and Stolarski, R. S.: Changes in Column Ozone Correlated with the Stratospheric EP Flux, J. Meteorol. Soc. Jpn., 80, 849-862, doi:10.2151/jmsj.80.849, 2002.

Rosenlof, K. H.: Seasonal cycle of the residual mean meridional circulation in the stratosphere, J. Geophys. Res., 100, 5173-5191, doi:10.1029/94JD03122, 1995.

Russell, A., Milford, J., Bergin, M. S., McBride, S., McNair, L., Yang, Y., Stockwell, W. R., and Croes, B.: Urban Ozone Control and Atmospheric Reactivity of Organic Gases, Science, 269, 491-495, doi:10.1126/science.269.5223.491, 1995.

Saiz-Lopez, A., Lamarque, J. F., Kinnison, D. E., Tilmes, S., Ordóñez, C., Orlando, J. J., Conley, A. J., Plane, J. M. C., Mahajan, A. S., Sousa Santos, G., Atlas, E. L., Blake, D. R., Sander, S. P., Schauffler, S., Thompson, A. M., and Brasseur, G.: Estimating the climate significance of halogen-driven ozone loss in the tropical marine troposphere, Atmos. Chem. Phys., 12, 3939-3949, doi:10.5194/acp-12-3939-2012, 2012.

Sanderson, M. G., Jones, C. D., Collins, W. J., Johnson, C. E., and Derwent, R. G.: Effect of climate change on isoprene emissions and surface ozone levels, Geophys. Res. Lett., 30, 1936, doi:10.1029/2003GL017642, 2003.

Sanderson, M. G., Collins, W. J., Hemming, D. L., and Betts, R. A.: Stomatal conductance changes due to increasing carbon dioxide levels: Projected impact on surface ozone levels, Tellus B, 59, 404-411, doi:10.1111/j.1600-0889.2007.00277.x, 2007.

Santer, B. D., Sausen, R., Wigley, T. M. L., Boyle, J. S., AchutaRao, K., Doutriaux, C., Hansen, J. E., Meehl, G. A., Roeckner, E., Ruedy, R., Schmidt, G., and Taylor, K. E.: Behavior of tropopause height and atmospheric temperature in models, reanalyses, and observations: Decadal changes, J. Geophys. Res., 108, 4002, doi:10.1029/2002JD002258, 2003a.

Santer, B. D., Wehner, M. F., Wigley, T. M. L., Sausen, R., Meehl, G. A., Taylor, K. E., Ammann, C., Arblaster, J., Washington, W. M., Boyle, J. S., and Brüggemann, W.: Contributions of An- thropogenic and Natural Forcing to Recent Tropopause Height Changes, Science, 301, 479-483, doi:10.1126/science.1084123, 2003 b.

Schumann, U. and Huntrieser, H.: The global lightning-induced nitrogen oxides source, Atmos. Chem. Phys., 7, 3823-3907, doi:10.5194/acp-7-3823-2007, 2007.

Shindell, D. T., Faluvegi, G., and Bell, N.: Preindustrial-to-presentday radiative forcing by tropospheric ozone from improved simulations with the GISS chemistry-climate GCM, Atmos. Chem. Phys., 3, 1675-1702, doi:10.5194/acp-3-1675-2003, 2003.

Shindell, D. T., Faluvegi, G., Lacis, A., Hansen, J. E., Ruedy, R., and Aguilar, E.: Role of tropospheric ozone increases in 20th-century climate change, J. Geophys. Res., 111, D08302, doi:10.1029/2005JD006348, 2006a.

Shindell, D. T., Faluvegi, G., Stevenson, D. S., Krol, M. C., Emmons, L. K., Lamarque, J.-F., Pétron, G., Dentener, F. J., Ellingsen, K., Schultz, M. G., Wild, O., Amann, M., Atherton, C. S., Bergmann, D. J., Bey, I., Butler, T., Cofala, J., Collins, W. J., Derwent, R. G., Doherty, R. M., Drevet, J., Eskes, H. J., Fiore, A. M., Gauss, M., Hauglustaine, D. A., Horowitz, L. W., Isaksen, I. S. A., Lawrence, M. G., Montanaro, V., Müller, J.-F., Pitari, G., Prather, M. J., Pyle, J. A., Rast, S., Rodriguez, J. M., Sanderson, M. G., Savage, N. H., Strahan, S. E., Sudo, K., Szopa, S., Unger, N., van Noije, T. P. C., and Zeng, G.: Multimodel simulations of carbon monoxide: Comparison with observations and projected near-future changes, J. Geophys. Res., 111, D19306, doi:10.1029/2006JD007100, 2006b.

Shindell, D. T., Faluvegi, G., Unger, N., Aguilar, E., Schmidt, G. A., Koch, D., Bauer, S. E., and Miller, R. L.: Simulations of preindustrial, present-day, and 2100 conditions in the NASA GISS composition and climate model G-PUCCINI, Atmos. Chem. Phys., 6, 4427-4459, doi:10.5194/acp-6-4427-2006, 2006c.

Shindell, D. T., Chin, M., Dentener, F. J., Doherty, R. M., Faluvegi, G., Fiore, A. M., Hess, P. G., Koch, D., MacKenzie, I. A., Sanderson, M. G., Schultz, M. G., Schulz, M., Stevenson, D. S., Teich, H., Textor, C., Wild, O., Bergmann, D. J., Bey, I., Bian, H., Cuvelier, C., Duncan, B. N., Folberth, G. A., Horowitz, L. W., Jonson, J., Kaminski, J. W., Marmer, E., Park, R., Pringle, K. J., Schroeder, S., Szopa, S., Takemura, T., Zeng, G., Keating, T. J., and Zuber, A.: A multi-model assessment of pollution transport to the Arctic, Atmos. Chem. Phys., 8, 5353-5372, doi:10.5194/acp-8-5353-2008, 2008.

Shindell, D. T., Lamarque, J.-F., Schulz, M., Flanner, M. G., Jiao, C., Chin, M., Young, P. J., Lee, Y. H., Rotstayn, L., Milly, G., Faluvegi, G., Balkanski, Y., Collins, W. J., Conley, A. J., Dalsøren, S. B., Easter, R. C., Ghan, S. J., Horowitz, L. W., Liu, X., Myhre, G., Nagashima, T., Naik, V., Rumbold, S. T., Skeie, R. B., Sudo, K., Szopa, S., Takemura, T., Voulgarakis, A., and Yoon, J.-H.: Radiative forcing in the ACCMIP historical and future climate simulations, Atmos. Chem. Phys. Discuss., 12, 2110521210, doi:10.5194/acpd-12-21105-2012, 2012.

Sitch, S., Cox, P. M., Collins, W. J., and Huntingford, C.: Indirect radiative forcing of climate change through ozone effects on the land-carbon sink, Nature, 448, 791-794, doi:10.1038/nature06059, 2007.

SPARC-CCMVal: SPARC Report on the Evaluation of ChemistryClimate Models, 2010.

Stainforth, D. A., Allen, M. R., Tredger, E. R., and Smith, L. A.: Confidence, uncertainty and decision-support relevance in cli- 
mate predictions, Phil. Trans. Roy. Soc. A, 365, 2145-2161, doi:10.1098/rsta.2007.2074, 2007.

Stevenson, D. S., Johnson, C. E., Collins, W. J., Derwent, R. G., and Edwards, J. M.: Future estimates of tropospheric ozone radiative forcing and methane turnover - the impact of climate change, Geophys. Res. Lett., 27, 2073-2076, 2000.

Stevenson, D. S., Doherty, R. M., Sanderson, M. G., Johnson, C. E., Collins, W. J., and Derwent, R. G.: Impacts of climate change and variability on tropospheric ozone and its precursors, Faraday Discuss., 130, 41-57, doi:10.1039/b417412g, 2005.

Stevenson, D. S., Dentener, F. J., Schultz, M. G., Ellingsen, K., van Noije, T. P. C., Wild, O., Zeng, G., Amann, M., Atherton, M., Bell, N., Bergmann, D. J., Bey, I., Bulter, T., Cofala, J., Collins, W. J., Derwent, R. G., Doherty, R. M., Drevet, J., Eskes, H. J., Fiore, A. M., Gauss, M., Hauglustaine, D. A., Horowitz, L. W., Isaksen, I. S. A., Krol, M. C., Lamarque, J.-F., Lawrence, M. G., Montanaro, V., Müller, J.-F., Pitari, G., Prather, M. J., Pyle, J. A., Rast, S., Rodriguez, J. M., Sanderson, M. G., Savage, N. H., Shindell, D. T., Strahan, S. E., Sudo, K., and Szopa, S.: Multimodel ensemble simulations of present-day and near-future tropospheric ozone, J. Geophys. Res., 111, D08301, doi:10.1029/2005JD006338, 2006.

Stevenson, D. S., Young, P. J., Naik, V., Lamarque, J. F., Shindell, D. T., Voulgarakis, A., Skeie, R. B., Dalsøren, S. B., Myhre, G., Berntsen, T. K., Folberth, G. A., Rumbold, S. T., Collins, W. J., MacKenzie, I. A., Doherty, R. M., Zeng, G., van Noije, T. P. C., Strunk, A., Bergmann, D., Cameron-Smith, P., Plummer, D. A., Strode, S. A., Horowitz, L., Lee, Y. H., Szopa, S., Sudo, K., Nagashima, T., Josse, B., Cionni, I., Righi, M., Eyring, V., Conley, A., Bowman, K. W., and Wild, O.: Tropospheric ozone changes, radiative forcing and attribution to emissions in the Atmospheric Chemistry and Climate Model Inter-comparison Project (ACCMIP), Atmos. Chem. Phys. Discuss., 12, 2604726097, doi:10.5194/acpd-12-26047-2012, 2012.

Stolarski, R. S. and Frith, S. M.: Search for evidence of trend slowdown in the long-term TOMS/SBUV total ozone data record: the importance of instrument drift uncertainty, Atmos. Chem. Phys., 6, 4057-4065, doi:10.5194/acp-6-4057-2006, 2006.

Sudo, K., Takahashi, M., and Akimoto, H.: Future changes in stratosphere-troposphere exchange and their impacts on future tropospheric ozone simulations, Geophys. Res. Lett., 30, 2256, doi:10.1029/2003GL018526, 2003.

Taylor, K. E., Stouffer, R. J., and Meehl, G. A.: An Overview of CMIP5 and the Experiment Design, Bull. Am. Meteorol. Soc., 93, 485-498, doi:10.1175/BAMS-D-11-00094.1, 2012.

Tebaldi, C., Arblaster, J. M., and Knutti, R.: Mapping model agreement on future climate projections, Geophys. Res. Lett., 38, L23701, doi:10.1029/2011GL049863, 2011.

Thompson, A. M., Stewart, R. W., Owens, M. A., and Herwehe, J. A.: Sensitivity of tropospheric oxidants to global chemical and climate change, Atmos. Environ., 23, 519-532, doi:10.1016/0004-6981(89)90001-2, 1989.

Thompson, A. M., Witte, J. C., Oltmans, S. J., Schmidlin, F. J., Logan, J. A., Fujiwara, M., Kirchoff, V. W. J. H., Posny, F., Coetzee, G. J. R., Hoegger, B., Kawakami, S., Ogawa, T., Fortuin, J. P. F., and Kelder, H. M.: Southern Hemisphere Additional Ozonesondes (SHADOZ) 1998-2000 tropical ozone climatology 2. Tropospheric variability and the zonal wave-one, J. Geophys. Res., 108, 8241, doi:10.1029/2002JD002241, 2003.
Tilmes, S., Lamarque, J. F., Emmons, L. K., Conley, A., Schultz, M. G., Saunois, M., Thouret, V., Thompson, A. M., Oltmans, S. J., Johnson, B., and Tarasick, D.: Technical Note: Ozonesonde climatology between 1995 and 2011: description, evaluation and applications, Atmos. Chem. Phys., 12, 74757497, doi:10.5194/acp-12-7475-2012, 2012.

van Vuuren, D. P., Edmonds, J., Kainuma, M., Riahi, K., Thomson, A., Hibbard, K., Hurtt, G. C., Kram, T., Krey, V., Lamarque, J.-F., Masui, T., Meinshausen, M., Nakicenovic, N., Smith, S. J., and Rose, S. K.: The representative concentration pathways: an overview, Clim. Change, 109, 5-31, doi:10.1007/s10584-0110148-z, 2011.

Volz, A. and Kley, D.: Evaluation of the Montsouris series of ozone measurements made in the nineteenth century, Nature, 332, 240 242, doi:10.1038/332240a0, 1988.

Voulgarakis, A., Naik, V., Lamarque, J.-F., Shindell, D. T., Young, P. J., Prather, M. J., Wild, O., Field, R. D., Bergmann, D., CameronSmith, P., Cionni, I., Collins, W. J., Dalsøren, S. B., Doherty, R. M., Eyring, V., Faluvegi, G., Folberth, G. A., Horowitz, L. W., Josse, B., McKenzie, I. A., Nagashima, T., Plummer, D. A., Righi, M., Rumbold, S. T., Stevenson, D. S., Strode, S. A., Sudo, K., Szopa, S., and Zeng, G.: Analysis of present day and future $\mathrm{OH}$ and methane lifetime in the ACCMIP simulations, Atmos. Chem. Phys. Discuss., 12, 22945-23005, doi:10.5194/acpd-1222945-2012, 2012.

West, J. J., Fiore, A. M., Horowitz, L. W., and Mauzerall, D. L.: Global health benefits of mitigating ozone pollution with methane emission controls, Proc. Natl. Acad. Sci. USA, 103, 3988-3993, doi:10.1073/pnas.0600201103, 2006.

West, J. J., Fiore, A. M., Naik, V., Horowitz, L. W., Schwartzkopf, M. D., and Mauzerall, D. L.: Ozone air quality and radiative forcing consequences of changes in ozone precursor emissions, Geophys. Res. Lett., 34, L06806, doi:10.1029/2006GL029173, 2007.

West, J. J., Fiore, A. M., and Horowitz, L. W.: Scenarios of methane emission reductions to 2030: abatement costs and co-benefits to ozone air quality and human mortality, Clim. Change, 114, 441461, doi:10.1007/s10584-012-0426-4, 2012.

Wiedinmyer, C., Tie, X., Guenther, A. B., Neilson, R., and Granier, C.: Future changes in biogenic isoprene emissions: How might they affect regional and global atmospheric chemistry?, Earth Interactions, 10, Paper No. 3, doi:10.1175/EI174.1, 2006.

Wild, O.: Modelling the global tropospheric ozone budget: exploring the variability in current models, Atmos. Chem. Phys., 7, 2643-2660, doi:10.5194/acp-7-2643-2007, 2007.

Wild, O. and Palmer, P. I.: How sensitive is tropospheric oxidation to anthropogenic emissions?, Geophys. Res. Lett., 35, L22802, doi:10.1029/2008GL035718, 2008.

Wild, O., Fiore, A. M., Shindell, D. T., Doherty, R. M., Collins, W. J., Dentener, F. J., Schultz, M. G., Gong, S., MacKenzie, I. A., Zeng, G., Hess, P., Duncan, B. N., Bergmann, D. J., Szopa, S., Jonson, J. E., Keating, T. J., and Zuber, A.: Modelling future changes in surface ozone: a parameterized approach, Atmos. Chem. Phys., 12, 2037-2054, doi:10.5194/acp-12-20372012, 2012.

Williams, E. R.: The global electrical circuit: A review, Atmos. Res., 91, 140-152, doi:10.1016/j.atmosres.2008.05.018, 2009.

Worden, H. M., Logan, J. A., Worden, J. R., Beer, R., Bowman, K., Clough, S. A., Eldering, A., Fisher, B. M., Gunson, M. R., Herman, R. L., Kulawik, S. S., Lampel, M. C., Luo, M., Megret- 
skaia, I. A., Osterman, G. B., and Shephard, M. W.: Comparisons of Tropospheric Emission Spectrometer (TES) ozone profiles to ozonesondes: Methods and initial results, J. Geophys. Res., 112, D03309, doi:10.1029/2006JD007258, 2007.

Wu, S., Mickley, L. J., Jacob, D. J., Logan, J. A., Yantosca, R. M., and Rind, D. H.: Why are there large differences between models in global budgets of tropospheric ozone?, J. Geophys. Res., 112, D05302, doi:10.1029/2006JD007801, 2007.

Wu, S., Mickley, L. J., Jacob, D. J., Rind, D. H., and Streets, D. G.: Effects of 2000-2050 changes in climate and emissions on global tropospheric ozone and the policy-relevant background surface ozone in the United States, J. Geophys. Res., 113, D18312, doi:10.1029/2007JD009639, 2008.

Young, P. J., Arneth, A., Schurgers, G., Zeng, G., and Pyle, J. A.: The $\mathrm{CO}_{2}$ inhibition of terrestrial isoprene emission significantly affects future ozone projections, Atmos. Chem. Phys., 9, 27932803, doi:10.5194/acp-9-2793-2009, 2009.

Zeng, G. and Pyle, J. A.: Changes in tropospheric ozone between 2000 and 2100 modeled in a chemistry-climate model, Geophys. Res. Lett., 30, 1392, doi:10.1029/2002GL016708, 2003.

Zeng, G., Pyle, J. A., and Young, P. J.: Impact of climate change on tropospheric ozone and its global budgets, Atmos. Chem. Phys., 8, 369-387, doi:10.5194/acp-8-369-2008, 2008.
Zeng, G., Morgenstern, O., Braesicke, P., and Pyle, J. A.: Impact of stratospheric ozone recovery on tropospheric ozone and its budget, Geophys. Res. Lett., 37, L09805, doi:10.1029/2010GL042812, 2010.

Zhang, L., Jacob, D. J., Liu, X., Logan, J. A., Chance, K., Eldering, A., and Bojkov, B. R.: Intercomparison methods for satellite measurements of atmospheric composition: application to tropospheric ozone from TES and OMI, Atmos. Chem. Phys., 10, 4725-4739, doi:10.5194/acp-10-4725-2010, 2010.

Zhang, Q., Streets, D. G., Carmichael, G. R., He, K. B., Huo, H., Kannari, A., Klimont, Z., Park, I. S., Reddy, S., Fu, J. S., Chen, D., Duan, L., Lei, Y., Wang, L. T., and Yao, Z. L.: Asian emissions in 2006 for the NASA INTEX-B mission, Atmos. Chem. Phys., 9, 5131-5153, doi:10.5194/acp-9-5131-2009, 2009.

Ziemke, J. R., Chandra, S., Labow, G. J., Bhartia, P. K., Froidevaux, L., and Witte, J. C.: A global climatology of tropospheric and stratospheric ozone derived from Aura OMI and MLS measurements, Atmos. Chem. Phys., 11, 9237-9251, doi:10.5194/acp11-9237-2011, 2011. 